Türkiye Jeoloji Bülteni
Geological Bulletin of Turkey
$65(2022) 1-34$
doi:10.25288/tjb.975220

\title{
Cihanpaşa (Yozgat) Bölgesinin Güney Kesimindeki Manganez Cevherleşmesinin Jeokimyasal Özellikleri ve Kökeni
}

The Genesis and Geochemical Characteristics of Manganese Mineralization in the Southern Part of the Cihanpaşa (Yozgat) Area

\section{Selman Aydoğan (D)}

Balıkesir Üniversitesi, Mühendislik Fakültesi, Jeoloji Mühendisliği Bölümü, Balıkesir

\begin{tabular}{|c|c|c|}
\hline \multirow{2}{*}{ • Geliş/Received: 30.07 .2021} & - Düzeltilmiş Metin Geliş/Revised Manuscr & - Kabul/Accepted: 01.09.2021 \\
\hline & - Çevrimiçi Yayın/Available online: 30.09.2021 & 01.2022 \\
\hline
\end{tabular}

Öz: Türkiye'de Neotetis Okyanusu'nun kuzey kolunun kalıntısı olan İzmir-Ankara-Erzincan kenet zonunun (İAESZ) ofiyolitik melanj kompleksleri birçok manganez oksit yataklarına ev sahipliği yapmaktadır. Bu yataklar, melanj ünitelerine ait olan kırmızı-menekşe renkli radyolaryalı çört blokları içerisinde gözlenmektedir. Bu melanj birliklerinden, Artova melanjı Kırşehir Masifi (Orta Türkiye)'nin kuzey kesiminde İAESZ boyunca yayılım sunmaktadır ve aynı zamanda altere serpantinit ve radyolaryalı çört blokları, yastık lav, pelajik kireçtaşı bloklarından meydana gelmektedir. Cihanpaşa (Yozgat, İç Anadolu) bölgesinden Mn-oksit cevherleşmeleri, bu oluşumların kökeni, paleoredoks özellikleri ve depolanma ortamlarını ortaya koymak için analiz edilmiştir. Cevherleşmelerinin mineral parajenezi yaygın olarak braunit, pirolusit, psilomelan ve kuvars minerallerinden oluşmaktadır. Jeokimyasal olarak, yüksek Mn/Fe (60,2), düşük $\Sigma \mathrm{NYE}$ (15,75 ppm), $\mathrm{Cu}+\mathrm{Ni}+\mathrm{Co}(730 \mathrm{ppm})$, negatif Ce anomalisi ve hafif negatif $\mathrm{Y} / \mathrm{Y}^{*}$ anomalisi $(0,87)$ Cihanpaşa manganez cevherleşmelerinin denizaltı bir hidrotermal sistem ile oluştuğunu ortaya koymaktadır. Negatif Ce/Ce* anomalisi $(0,33)$, düşük $\mathrm{Ce}_{\text {anom }}$ değerleri $(<-0,54)$, redoks göstergeler $[\mathrm{V} /(\mathrm{V}$ $+\mathrm{Ni})=0,43 ; \mathrm{Ni} / \mathrm{Co}=0,51, \mathrm{~V} / \mathrm{Mo}=6,15)]$ çalış1lan manganez cevherleşmelerinin hidrotermal sistem tarafından oksijenli bir sedimanter ortamda oluştuğuna işaret etmektedir. Dahası, hafif pozitif ve negatif Eu anomalisi $(0,84)$, yüksek $\mathrm{La}_{\mathrm{sn}} / \mathrm{Ce}_{\mathrm{sn}}(3,96)$, düşük $\mathrm{Al} /(\mathrm{Al}+\mathrm{Fe})(0,34)$ ve $\Sigma \mathrm{NYE} / \mathrm{Fe}\left(30,7 \times 10^{-4}\right)$ oranları Cihanpaşa manganez oksit cevherleşmelerinin Neotetis Okyanusu'nun yaklaşık yayılma sırtına nispeten yakın düşük sıcaklıklı hidrotermal sistemin etkisi ile şekillenmiş olduğunu göstermektedir.

Anahtar Kelimeler: Cihanpaşa, Hidrotermal, İç Anadolu, manganez oksit cevherleşmesi, radyolaryalı çört, Yozgat.

Abstract: Late Cretaceous ophiolitic mélange complexes of the Izmir-Ankara-Erzincan Suture Zone (IAESZ) that is the remnant of the northern branch of the Neotethys Ocean host numerous manganese oxide deposits in Turkey. These deposits are observed within the red-violet radiolarian chert blocks belonging to mélange units. Of these mélange units, the Artova mélange is observed along the IAESZ in the northern part of the Kirşehir Massif, central Turkey, and is made up mainly of pelagic limestone, pillow basalt, radiolarian-chert blocks, and highly altered serpentinite. Mn-oxide mineralizations from Cihanpaşa (Yozgat, central Anatolia) region were analysed in order to determine their depositional conditions, paleo-redox signatures, origin and source. These mineralizations are composed mainly of an alternation of radiolarian cherts and mudstones that overlie altered pillow basalt in an overturned fold. Based on petrographic studies, the mineral paragenesis of the manganese oxide mineralizations is comprised predominantly of braunite, pyrolusite, pysilomelane and quartz. Geochemically, high $\mathrm{Mn} / \mathrm{Fe}$ (60.2), low SREE (15.75 ppm) and $\mathrm{Cu}+\mathrm{Ni}+\mathrm{Co}(730 \mathrm{ppm})$, and a negative Ce anomaly and weakly negative $Y / Y^{*}$ anomaly (0.87) 
suggest that the Cihanpaşa manganese mineralizations formed in a submarine hydrothermal system. A negative Cel $C e^{*}$ anomaly (0.33), low Ce $e_{\text {anom }}$ values $(<-0.54)$, and redox-sensitive tracers $[V /(V+N i)=0.43, \mathrm{Ni} / \mathrm{Co}=0.51$, $V / M o=6.15)]$ indicate that the manganese mineralization was formed by a hydrothermal system in an oxygenated marine sedimentary environment. Further, a weakly positive and negative Eu anomaly (0.84), high $L a_{s n} / \mathrm{Ce}_{s n}(3.96)$, low $\mathrm{Al} /(\mathrm{Al}+\mathrm{Fe})(0.34)$ and $\Sigma R E E / \mathrm{Fe}\left(30.7 \times 10^{-4}\right)$ ratios highlighted that the Cihanpaşa manganese mineralizations were formed via impact of a low-T hydrothermal system, which is relatively close to the spreading ridge of the IzmirAnkara-Erzincan Ocean.

Keywords: Central Anatolia, Cihanpaşa, hydrothermal, manganese oxide mineralization, radiolarian chert, Yozgat.

\section{GíRiş}

Manganez, demir-çelik, kimya, elektronik ve batarya endüstrisindeki kullanımlarından dolayı ekonomi için önemli ham maddelerden biridir. Son zamanlarda endüstride manganez kullanımının birçoğu çelik endüstrisinde manganez bileşiklerinin (ferromanganez, silikomanganez) yapımında tüketilmektedir. Son yıllarda, manganez cevher üretimi dünya genelinde yüksek oranda artmıştır (Li vd., 2019). Günümüzde, mangan dünya genelinde yayılım sunan ve farklı kayaç litolojileri içerisinde yer alan yataklardan elde edilmektedir (Petersen vd., 2016). Dünya'da farklı jenetik tiplerde gözlenen manganez yatakları Güney Afrika, Ukrayna, Brezilya, Avustralya, Gabon, Çin, Hindistan, Gana, Meksika, Kazakistan ve Malezya'da bulunmaktadır. Güney Afrika, Ukrayna, Brezilya global rezervin \%60'ına karşılık gelmektedir. $\mathrm{Bu}$ rezervlerden, Güney Afrika, Avustralya, Brezilya ve Gabon yüksek tenörlü (Mn > \%44); Hindistan, Kazakistan, Meksika orta tenörlü (Mn \%30-40); Ukrayna ve Gana düşük tenörlü ( $\mathrm{Mn}<$ \%30) manganez cevherleşmelerine ev sahipliği yapmaktadır (Li vd., 2019; USGS, 2019; Şaşmaz vd., 2020; 2021).

Doğal metal kaynakları, dünya yüzeyinin 1/3'ün den daha az kısmını temsil eden karalardaki cevher yataklarından elde edilmektedir. Bununla birlikte, tüketilen cevherleşmelerin yerine yüksek tenör değerlerine sahip cevher alanlarının tespit edilmesi zorlaştığından (Petersen vd., 2016), modern okyanus havzalarında gelecekteki metallerin ana kaynağı olarak düşünülen farklı tipteki manganez nodülleri ve kobalt bakımından zengin ferromanganez kabukları üzerine güncel araştırmalar devam etmektedir (Hein vd., 2010). Okyanus ortas1 yayılma sırtlarına yakın bölgeler, deniz altı sülfid yatakları ile birlikte zengin metal içeriğine sahip sedimanterkayaçlar içermektedirler. $\mathrm{Bu}$ sedimanter kayaçlar yüksek metal içeriğinin $(\mathrm{Co}, \mathrm{Cu}, \mathrm{Ni}, \mathrm{Mo}, \mathrm{Te}, \mathrm{Li})$ yanısıra, zengin nadir yer elementleri (NYE) potansiyeline de sahiptir (Hein vd., 2010; 2014). Günümüzde modern yayılma sırtları boyunca zengin metal içeriğine sahip olan ferromanganez kabuklar, mangan nodülleri ile birlikte sülfid yatakları üzerinde önemli çalışmalar gerçekleştirilmektedir. Modern okyanuslardaki araştırmalar ile birlikte derin deniz madenciliği de tartışılmaya başlanmıştır. Derin deniz madenciliği, okyanuslarda 200 m'nin altında denizden madenlerin çıkarılması işlemi olarak bilinmektedir (IUCN, 2018). Son zamanlarda, metal fiyatlarındaki artış ve karasal ortamlardaki metalik cevher yataklarının tüketimiyle birlikte derin deniz madenciliğine olan ilgi artmaktadır. Bu büyük ölçüde, $\mathrm{Cu}, \mathrm{Ni}, \mathrm{Al}, \mathrm{Mn}$, $\mathrm{Zn}$, Li ve Co gibi metallerin karasal ortamlardaki tüketiminden ve bu metaller için yüksek teknoloji uygulamalarındaki talebin artmasından kaynaklanmaktadır (Petersen vd., 2016). Derin deniz madenciliğinde 40 yılı aşkın süredir yapılan büyük yatırım ve araştırmalara rağmen, denizel metal (Ni, Co, Zn) içeren nodüller ticari ölçekte yüzeye çıkarılamamıştır. Bu nedenle, derin deniz manganez ve Co-zengini Mn kabuklarının yeterli oranda gelecekte ticari ölçekte çıkarılamayacağı öngörülmektedir. Minimum düzeyde ekonomik olabilmesi için, nodüllerin y1l boyunca günde 
yaklaşı 5.000 tonluk bir oranda çıkarılması gerekmektedir ve nodüllerin $\mathrm{Ni}+\mathrm{Cu}+\mathrm{Co}$ içeriğinin \%2,5'dan fazla olması gerekmektedir (Glasby vd., 2015).

Farklı tipte manganez oluşumları, modern yada eski okyanusları içeren sedimanter ortamlarda oluşmakta (Roy, 1997; Polgari vd., 2012; Zarasvandi vd., 2013, 2016) ve yeryuvarının okyanus havzaları hakkında kıymetli bilgiler sunmaktadır (Hein vd., 1997; Nicholson vd., 1997). Manganez yatakları, mineraloji, kimyasal bileşim, tektonik ve depolanma ortamı temelinde, hidrotermal, hidrojenetik, diyajenetik ve biyojenetik (bakteri kökenli) yataklar olmak üzere dört ana grup içerisinde incelenmektedir (Bolton vd., 1988; Hein vd., 1997; 2008; Öksüz 2011a, b; Polgári vd., 2012). Bu yataklar arasında, hidrojenetik manganez yatakları, oksijenli ortamda deniz suyundan yavaş bir kimyasal çökelim (2$10 \mathrm{~mm} / \mathrm{my}$ ) ile oluşmaktadır (Glasby vd., 1987, 2015; Glasby, 2006). Ferromanganez yatakları (polimetalik yataklar, Co-zengini ferromanganez kabuklar) metal içerikleri bakımından oldukça zengindir. Polimetalik nodüller, bir çekirdek civarında düzensiz şekilde bantlı konsantrik mikro-tabakalar ile karakteristiktir (Halbach vd., 1981; Wegorzewski ve Kuhn, 2014). Cozengini ferromanganez kabuklar sedimanter veya volkanik kayaçlar ile temsil edilmektedir ve pelajik ortamlarda $\mathrm{Fe}-\mathrm{Mn}$ oksihidroksitlerin yavaş çökelimi ile oluşmaktadırlar (Dubinin vd., 2018). Diyajenetik yataklar, erken diyajenez süresince manganın direk olarak çökelimi ile oluşmaktadır. Fe-Mn bakımından zengin diyajenetik nodüller sediment-su yüzeyi yakınında veya yarı oksik sediment boşluk suyundaki metal iyonları ile meydana gelmektedirler (Wegorzewski ve Kuhn, 2014; Bau vd., 2014). Yarı oksijenli ortamdaki diyajenetik nodüller hemipelajik sedimanter ortamda bulunurken, oksijen bakımından zengin ortamda oluşan nodüller derin deniz ortamındaki oksik sedimentlerde gözlenmektedir (Dymond vd., 1984; Takematsu vd., 1989). Hidrotermal yataklar, hidrotermal solüsyonlardan Mn-oksit ve/veya Feoksihidroksitlerin çökelimi ile oluşmaktadırlar (Hein, 2004; Hein vd., 1997, 2008). Bu yataklar, ada yayı sistemleri, plaka içi denizdağları, okyanus ortas1 sırt bölgeleri gibi farklı tektonik ortamlarda meydana gelmektedirler (Roy 1997).

Ülkemizde, manganez oksit yatakları Triyas'tan Oligosen dönemine kadar geniş bir yaş aralığında oluşmuştur ve farklı tektonik ortamlarda gözlenmektedir (Kuşçu ve Gedikoğlu, 1989; Öztürk, 1997; Öztürk ve Hein, 1997; Öksüz 2011a ve b; Şaşmaz vd., 2014; Gültekin ve Balc1, 2018; Öztürk vd., 2019). Bu yataklar, 4 grup içerisinde sınıflanabilmektedir: 1) radyolaryalı çört birimleri içerisinde gözlenen yataklar (PaleoTetis Karakaya Kompleksi, Neotetis kenet zonlar1), 2) şeyl içerisindeki yataklar (batı Toridler), 3) volkanik yay ile ilişkili kayaçlar içerisindeki yataklar (doğu Pontidler), 4) sedimanter kayaçların ev sahipliği yaptığı yataklar (Trakya havzası). Bu manganez yataklarının birçoğu Tetis Okyanusu'nun evrimi ile ilişkilidir. Anadolu, Tetis Okyanusları'na ait kolların kapanması ile birçok mikro kıtasal parçaların birleşiminden meydana gelmiştir. Türkiye, kuzeyde Lavrasya ve güneyde Gondwana arasındaki çarpışma ile sonuçlanan Geç Kretase'de şekillenen Alp-Himalaya orojenik sistemin doğu-batı gidişli önemli bir bileşenidir (Şengör ve Y1lmaz 1981; Okay, 1986). Bu çarpışma, kuzeyde Pontidler ve güneyde AnatolidTorid bloğu arasında İzmir-Ankara-Erzincan Kenet Zonu (İAESZ) boyunca gelişmiştir. İAESZ, birçok ofiyolitik melanj birliklerinden meydana gelen, doğu Akdeniz bölgesindeki önemli kenet zonlarından biridir ve Neotetis Okyanusu'nun kuzey kolunu temsil etmektedir (Şengör ve Y1lmaz 1981). Manganez oksit yataklarının büyük bir çoğunluğu İAESZ boyunca ya da yakınında bulunan ofiyolitik melanj birliklerinde (Artova melanj1, Ankara melanj1, Dağküplü melanjı, Dağardı melanjı gibi) irili-ufaklı bloklar şeklinde gözlenen radyolaryalı çört litolojileri içerisinde mostra vermektedir. Bu yataklar açık 
ocak işletme metodu ile işletilmektedir ve yaygın olarak yüksek silisyum (\%30) ve mangan (\%30) içeriklerine sahiptir. $\mathrm{Bu}$ zon boyunca işletilen yatakların rezevleri $5.000-30.000$ ton arasında değişmektedir (Öztürk vd., 2019). Radyolaryalı çörtler ile ardalanmalı şekilde ve/veya bazen bu kayaçlar içerisinde çeşitli boyutlarda mercekler şeklinde gözlenen manganez oksit yatakları üzerinde bugüne kadar gerçekleştirilen detaylı mineralojik ve jeokimyasal çalışmalar kapsamında, bu yatakların İzmir-Ankara-Erzincan Neotetis okyanusunun denizaltı bir hidrotermal sistemi ile ilişkili olduğunu ortaya koymaktadır (Oygür, 1990; Koç vd., 2000; Karakuş vd., 2010; Öksüz 2011a, b; Öksüz ve Okuyucu, 2014; Kılıç vd., 2018; Öztürk, 1997; Öztürk vd., 2019).

$\mathrm{Bu}$ çalışma, Cihanpaşa (Yozgat) yöresinin güney kesiminde radyolaryalı çörtler ile ilişkili mangan cevherleşmeleri üzerine gerçekleştirilmiştir. Bölgede yastık lavlar ile pelajik kayaçlar arasında mangan nodülleri bulunmaktadır. Geçmiş zamanlarda işletilmiş olan ve mangan bakımından zengin nodüller ile ilgili toplamda 10 adet numunenin jeokimyasal analizleri yapılmıştır ( \% MnO: 70,4, \% $\mathrm{SiO}_{2}: 9,9$, $\% \mathrm{BaO}: 1,5, \mathrm{Cu}+\mathrm{Co}+\mathrm{Ni}: \% 0,15, \Sigma \mathrm{NYE}: 113$ ppm; yayımlanmamış veri) ve detay mineraloji üzerine çalışmalar Aarhus Üniversitesi (Danimarka)'nde devam etmektedir. Diğer taraftan, bölgedeki radyolaryalı çörtlerin ev sahipliğini yaptığ $\mathrm{Fe}$ $\mathrm{Mn}$ cevherleşmeleri çoğunlukla yüksek $\mathrm{Fe}_{2} \mathrm{O}_{3}$ ( \% \% 16), ve düşük $\mathrm{MnO}(\sim \% 9)$ değerlerine sahiptir (yayımlanmamış veri). Bu cevherleşmeler İzmirAnkara-Erzincan Okyanusu havzasındaki yayılma sırtına yakın şekilde oluşmuştur. Dolayısıyla, bölge detaylı bir şekilde incelendiğinde bu oluşumların sırt kısmına yakın olması ile birlikte bölgedeki Artova ofiyolit melanjı içerisinde farklı kayaç litolojilerinde metalik sülfid cevherleşmelerinin bulunma olasılığının arttığı ve maden aramalarının bölgede yoğunlaştırılması gerekliliğini ortaya konmuştur. Sonuç olarak, bu çalışma bölgedeki mangan cevherleşmelerinin jeokimyasal karakterinin ortaya konulması ve kökenine yaklaşımda bulunmak amacıyla gerçekleştirilmiştir.

\section{JEOLOJI}

İAESZ, Türkiye'nin kuzey kesiminde batıdan doğuya doğru yaklaşık olarak 2000 km uzunluğu olan birçok ofiyolitik melanj birimlerinden meydana gelen bir zondur. $\mathrm{Bu}$ kenet zonu boyunca zonu temsil eden melanj birlikleri, en iyi gözlendiği lokasyonlarda isimlendirilmiştir (örn: Bornova melanj1, Dağküplü melanj1, Ankara melanj1, Artova melanj1, Tekelidağ melanj1, Şahvelet melanj1). Bunlardan Artova melanj1, kuzeyde Sakarya Kitas1 ile güneyde Kırşehir Masifi arasında yeralmaktadır ve Ankara melanjının devamı şeklinde gözlenmektedir (Şekil 1a, b). Artova melanjının kuzey kesiminde Sakarya Kıtasına ait olan Tokat Masifi bulunmaktadır. Bu masif, Triyas yaşlı Karakaya Kompleksi'nden ve Jura-Kretase yaşlı karbonat örtüden meydana gelmektedir (Okay ve Göncüoğlu, 2004) ve Artova melanjının birimleri üzerine önemli bir bindirme fay1 ile itilmektedir (Y1lmaz vd., 1997; Bortolotti vd., 2013, 2018; Akçay ve Beyazpirinç, 2017). Artova melanjının belirli bir kısmını temsil eden Jura yaşlı radyolaryalı çörtlerin tektonik dilimleri, bölgede Eosen sonrası sıkışma rejimi süresince Karakaya Kompleksi'nin epimetamorfik kayaçları ile üst üste binmiş şekilde gözlenmektedir (Bozkurt vd., 1997). 


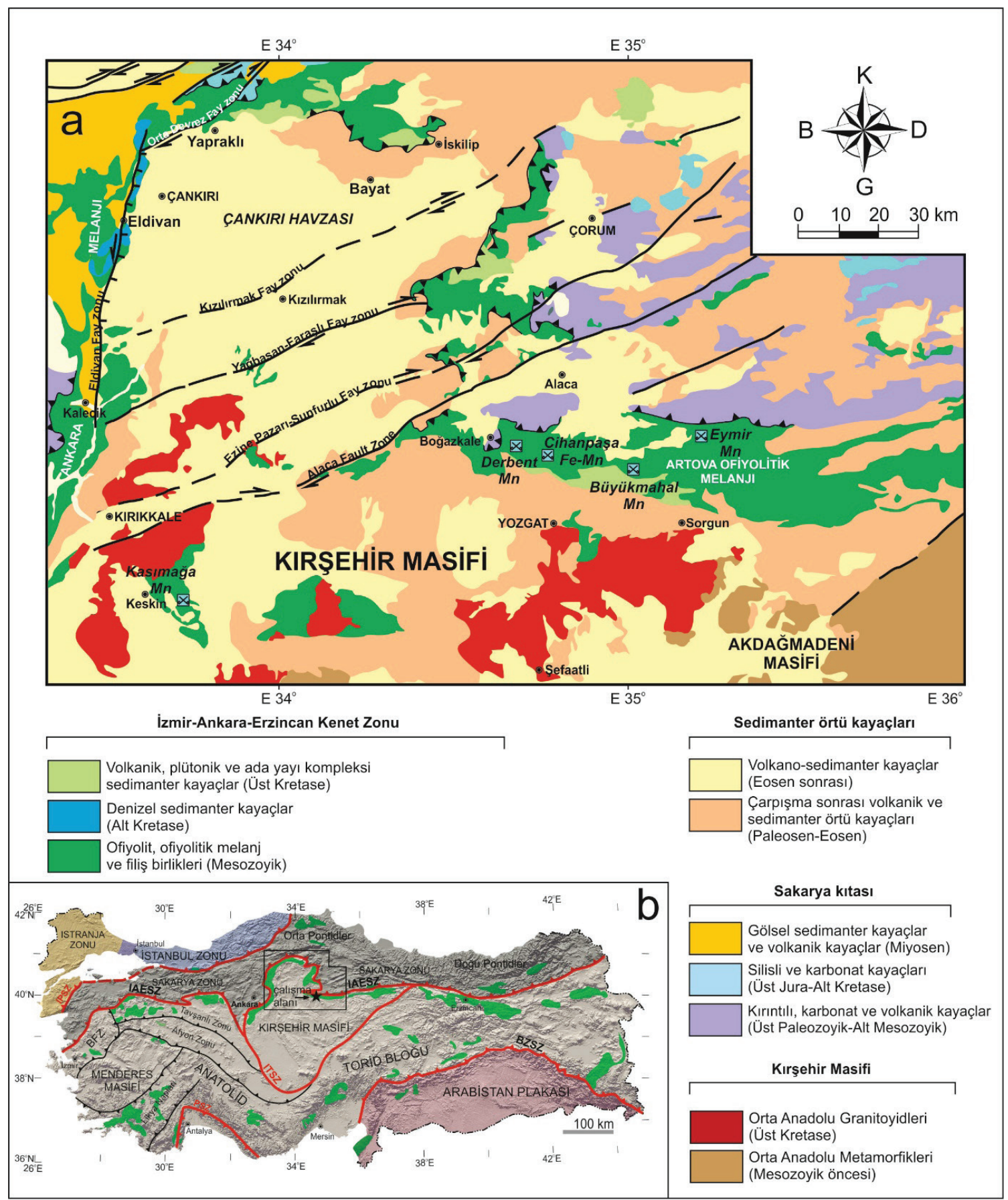

Şekil 1. a) Orta Anadolu'nun kuzey kesiminin jeoloji haritası (1/500.000 ölçekli jeoloji haritas1, MTA, 2002). Doğrultu atımlı faylar ve isimleri Yolsal-Çevikbilen vd. (2012)'den alınmıştır. b) Ofiyolit, ofiyolitik melanj kompleksleri ve ana kenet zonlarını gösteren kabartma harita (Şengör ve Yılmaz, 1981; Okay ve Tüysüz, 1999).

Figure 1. a) Geological map (modified after 1/500,000 Geological Map of Turkey, MTA 2002) of the northern part of Central Anatolia. The strike-slip faults and their names are from Yolsal-Çevikbilen et al., (2012). b) Relief map showing main suture zones and ophiolite-ophiolitic melange complex is from Şengör and Yllmaz (1981), and Okay and Tüysüz (1999). 
Artova melanj1, Kırşehir Masifi'nin temel kayaçları üzerinde allokton konumda bulunmaktadır. Bölgede radyolaryalı çörtler, İzmir-Ankara-Erzincan okyanusal litosfer ve dalma batma eklenir prizmanın farklı üyelerine ait olan ofiyolitik kayaçlar ile birlikte bloklar şeklinde bulunmaktadır. Melanj, irili ufaklı birçok radyolaryalı çört, neritik kireçtaşı, mafik volkanik ve serpantinit bloklarından meydana gelmektedir (Şekil 2). Kahverengimsi, kırmızımsı renkli derin deniz pelajik kayaçları bazaltik karakterli yastık lavlar üzerinde gözlenmektedir (Şekil 3ag). Cihanpaşa bölgesinde, bu kayaçlar düzgün tabakalı ve bazı lokasyonlarda oldukça güçlü kıvrımlanmalara sahiptir. İAESZ boyunca, farklı lokasyonlardan radyolaryalı çörtler ve mikritik kireçtaşlarından elde edilen paleontolojik yaşlar Orta Triyas ve Geç Kretase yaşları vermektedir (Bragin and Tekin, 1996; Tekin vd., 2002; Rojay vd., 2004; Göncüoğlu vd., 2006a, 2006b, 2010; Tekin vd., 2012; Sarıfakığlu vd., 2017; Bortolotti vd., 2018; Özkan vd., 2020).

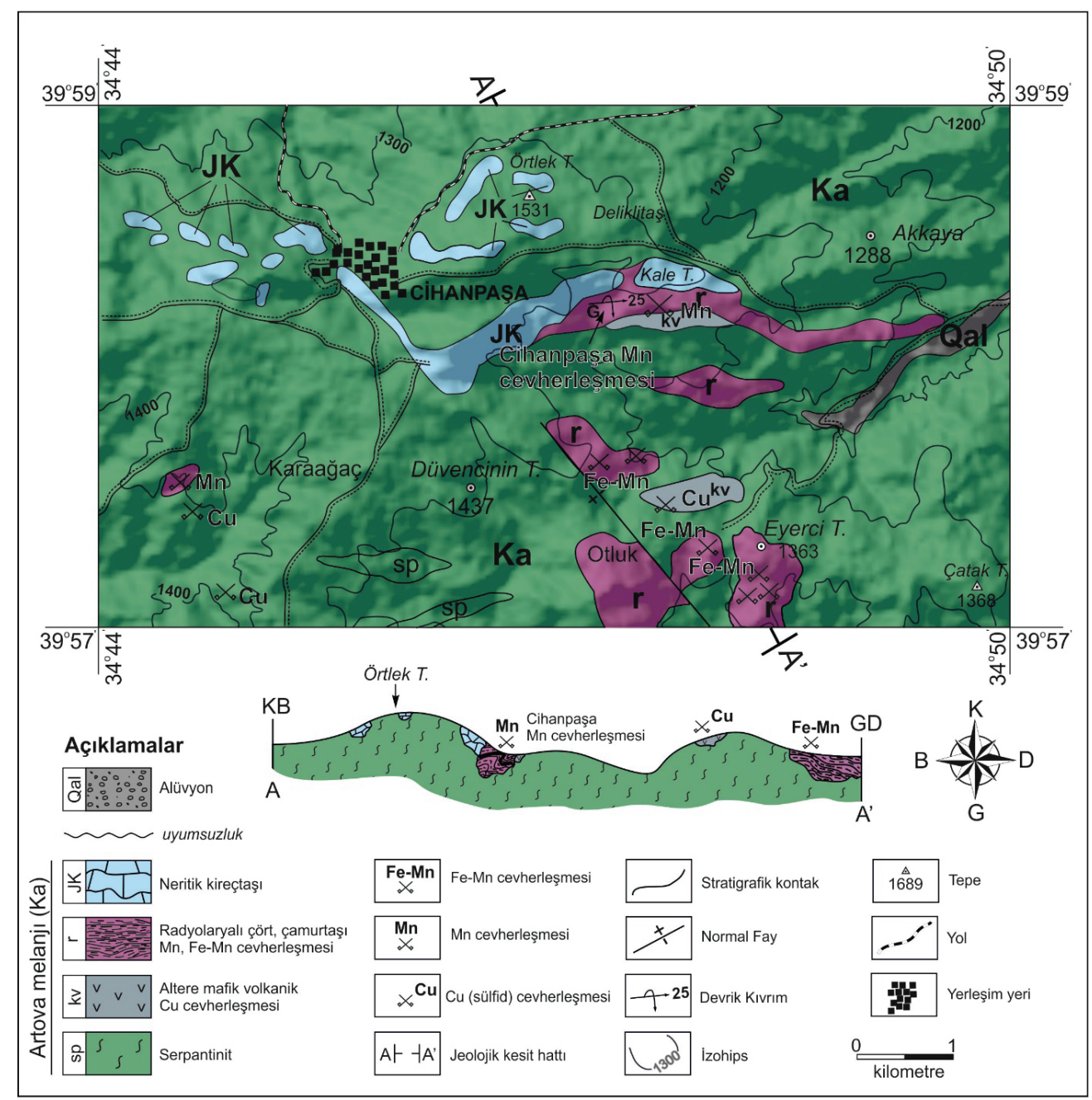

Şekil 2. Cihanpaşa (Yozgat) ve civarının jeoloji haritası (Akçay vd., 2007'den düzenlenmiştir) ve A-A' hattından geçen jeoloji enine kesiti.

Figure 2. Geological map of Cihanpaşa (Yozgat) and its surroundings (modified after Akçay et al., 2007) and crosssection along $A$-A'line. 

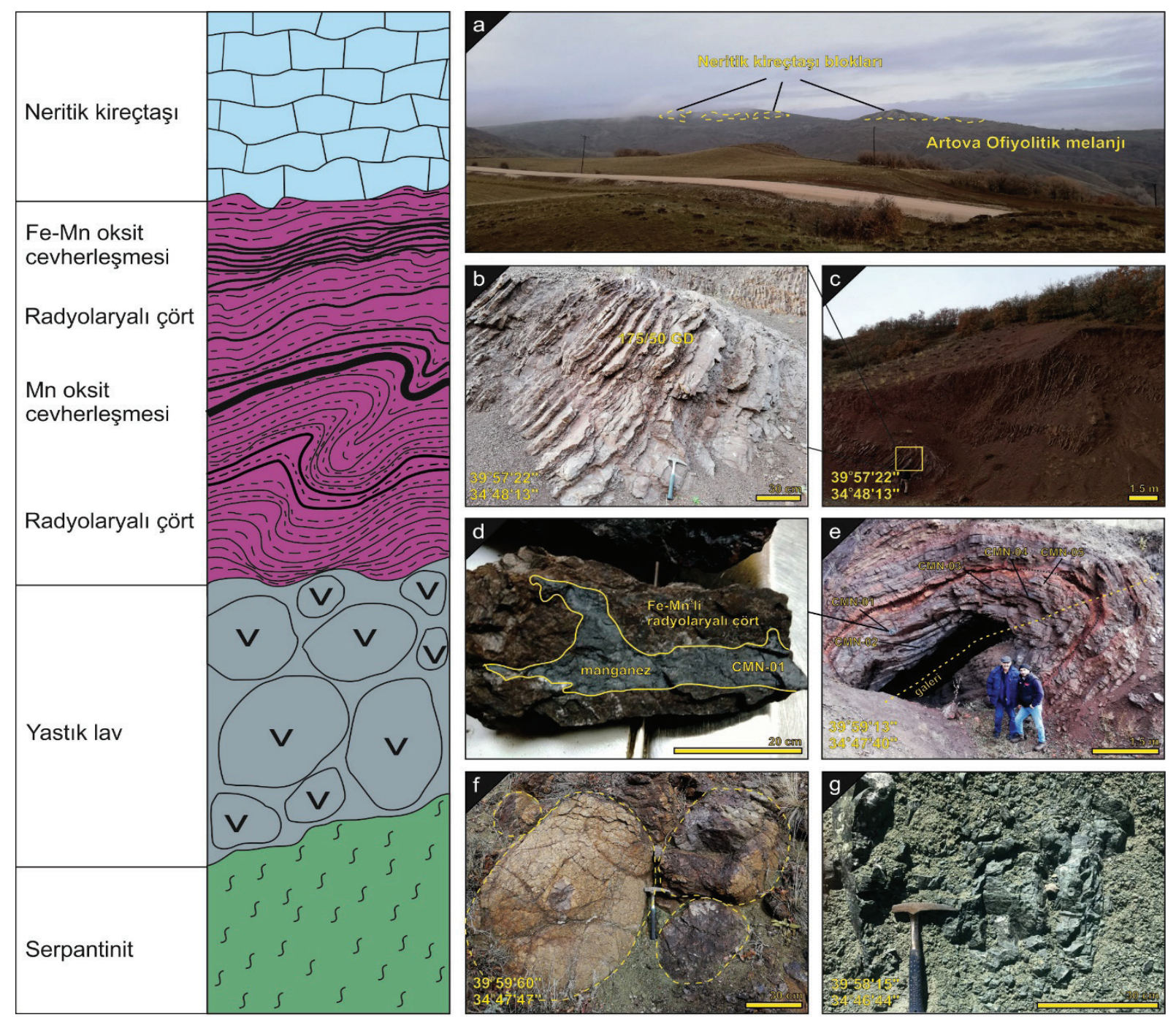

Şekil 3. Cihanpaşa (Yozgat) bölgesinde Artova ofiyolitik melanjının birimlerini gösteren basitleştirilmiş kolon kesit ve arazi fotoğrafları. a) Artova ofiyolitik melanjı ve içerisindeki kireçtaşı blokları b, c) çalışma alanının güney kesiminde gözlenen ince tabakalı radyolaryalı çört tabakaları d) manganez cevherleşmesi ve ana kayacını içeren el örneği, e) İşletilmiş bir manganez galerisi ve radyolaryalı çörtü içeren devrik kıvrım f) eski galeri yakınında yastık lavlar, g) melanj içerisinde gözlenen serpantinit mostrası.

Figure 3. Simplified columnar section and field photos from units of Artova ophiolitic melange in Cihanpaşa (Yozgat) region. a) Panoramic photo showing Artova ophiolitic melange and limestone blocks. b, c) Thin-bedded radiolarian chert layers exposed in south of studied area. d) Hand specimen including manganese mineralization and host rock. e) Overturned folding of radiolarian chert and pre-operated Mn gallery. f) Pillow lava near the old gallery. g) Serpentinite outcrop observed within the melange.

Yozgat ili genelinde, özellikle Artova ofiyolit melanjı içerisinde irili ufaklı birçok Mn-oksit yatakları bulunmaktadır. Bunlardan; Derbent, Büyükmahal ve Eymir cevherleşmeleri bilimsel anlamda çalışılmıştır (Şekil 1; Öksüz, 2011a ve b; Öksüz ve Okuyucu, 2014). Cihanpaşa Mn cevherleşmesi (39॰59'7,60”K, 3447'38,21'”D, $1371 \mathrm{~m}$; Şekil 2), Yozgat iline yaklaşık olarak 
$35 \mathrm{~km}$ kuzeyinde yer almaktadır ve lokasyon olarak Kale Tepe'nin güneybatı kesiminde bulunmaktadır (Şekil 2). Cevherleşme, derin deniz kökenli radyolaryalı çört birimleri ile uyumlu bir şekilde gözlenmektedir. $\mathrm{Bu}$ çalışmada, devrik kıvrım içerisinde radyolaryalı çört birimleri ile ardalanmalı olarak gözlenen manganez cevherleşmeleri üzerine örnekleme çalışması gerçekleştirilmiş ve analizleri yapılarak yorumlanmıştır (Şekil 3e).

\section{MATERYAL VE YÖNTEM}

Toplam 5 adet temsili numune, Cihanpaşa bölgesinin güney kesimindeki devrik bir antiklinal yapısı sunan radyolaryalı çörtler içerisindeki mangancevherleşmelerindenalınmıştır.Örneklerin analizleri, ACME Analiz Laboratuvarları (Vancouver, Kanada)'da gerçekleştirilmiştir. Kimyasal analizler için örnekler, 700 mesh'den geçecek şekilde öğütülmüştür. Ana elementler $\left(\mathrm{SiO}_{2}, \mathrm{TiO}_{2}, \mathrm{Al}_{2} \mathrm{O}_{3}, \mathrm{MnO}, \mathrm{MgO}, \mathrm{CaO}, \mathrm{K}_{2} \mathrm{O}, \mathrm{Na}_{2} \mathrm{O}\right.$, $\mathrm{P}_{2} \mathrm{O}_{5}$ ) ICP-AES yöntemiyle gerçekleştirilmiştir. Herbir örnek Ateşte Zayiat ölçümü için 1000 ${ }^{\circ} \mathrm{C}$ 'de 1 sitılmıştır. Eser elementler ve nadir toprak elementleri ICP-MS ile analiz edilmiştir. Dedeksiyon limitleri eser elementler için 0,18 ppm, ana elementler için \%0,01-0,1 ve nadir yer elementleri için 0,1-0,01 ppm'dir. Analizler Çizelge 1'de verilmiştir. Analiz kalitesi standart referans materyalleri temelinde (http:// acmelab.com/services/method-descriptions/ soiltill-and-sediment/) gerçekleştirilmiştir (Öztürk vd., 2016). Veriler, literatürde verilen diyagramlar üzerinde değerlendirilmiş ve gerekli yorumlamalar gerçekleştirilmiştir. Bu çalışmada bazı yorumlamalar için farklı hesaplamalar yapılmıştır. Şeyl, nadir yer elementleri içerikleri PAAS (McLennan, 1989) ve NASC (Gromet vd., 1984)'dan alınmıştır. Ce anomalisi, şeyl (PAAS, Post Archean Australian Shale), (NASC, North America Shale Composite)'e göre normalize edilerek hesaplanmıştır. Ce/Ce* ${ }_{\text {PAAS }}, 2 \times \mathrm{Ce}_{\text {PAAS }}$ $\left(\mathrm{La}_{\mathrm{PAAS}}+\mathrm{Pr}_{\mathrm{PAAS}}\right) ; \mathrm{Pr} / \mathrm{Pr} * 2 \times \operatorname{Pr}_{\mathrm{PAAS}} /\left(\mathrm{Ce}_{\mathrm{PAAS}}+\right.$ $\left.\mathrm{Nd}_{\text {PAAS }}\right) ; \quad \mathrm{Ce} / \mathrm{Ce}^{*}{ }_{\mathrm{NASC}}, \quad\left(\mathrm{Ce}_{\text {samp }} / \mathrm{Ce}_{\mathrm{NASC}}\right) /\left(2 * \mathrm{Pr}_{\text {samp }} /\right.$ $\left.\mathrm{Pr}_{\mathrm{NASC}}-\mathrm{Nd}_{\mathrm{NASC}}\right) ; \mathrm{Y} / \mathrm{Y}^{*}, 2 \times \mathrm{Y}_{\mathrm{PAAS}} /\left(\mathrm{Dy}_{\mathrm{PAAS}}+\right.$ $\left.\mathrm{Ho}_{\text {PAAS }}\right) ; \mathrm{Eu} / \mathrm{Eu}^{*}, \mathrm{Eu}_{\text {PAAS }} /\left(0,67 \times \mathrm{Sm}_{\text {PAAS }}+0,33 \times\right.$ $\mathrm{Tb}_{\text {PAAS }}$ ) (Murray, 1994; Murray vd., 1990, 1991; Bolhar vd., 2004; Bau ve Dulski, 1999).

Çizelge 1. Cihanpaşa (Yozgat, orta Türkiye) manganez cevherleşmelerinin ana, eser ve nadir toprak element içerikleri.

Table 1. Major, minor, and rare-earth element compositions of the Cihanpaşa (Yozgat, central Turkey) manganese mineralizations.

\begin{tabular}{|c|c|c|c|c|c|c|c|c|}
\hline Örnek & CMN-01-A & CMN-01-B & CMN-01-C & CMN-01-D & CMN-01-E & En az & En fazla & Ortalama \\
\hline $\mathrm{SiO}_{2}$ & 45,30 & 32,25 & 60,99 & 81,21 & 60,19 & 32,25 & 81,21 & 55,99 \\
\hline $\mathrm{Al}_{2} \mathrm{O}_{3}$ & 1,02 & 0,19 & 0,25 & 0,30 & 0,27 & 0,19 & 1,02 & 0,41 \\
\hline $\mathrm{Fe}_{2} \mathrm{O}_{3}$ & 1,17 & 0,50 & 0,57 & 0,58 & 0,60 & 0,50 & 1,17 & 0,68 \\
\hline $\mathrm{MgO}$ & 0,73 & 0,10 & 0,06 & 0,08 & 0,07 & 0,06 & 0,73 & 0,21 \\
\hline $\mathrm{CaO}$ & 0,63 & 0,86 & 0,32 & 0,21 & 0,32 & 0,21 & 0,86 & 0,47 \\
\hline $\mathrm{Na}_{2} \mathrm{O}$ & 0,01 & 0,01 & 0,01 & 0,01 & 0,01 & 0,01 & 0,01 & 0,01 \\
\hline $\mathrm{K}_{2} \mathrm{O}$ & 0,10 & 0,07 & 0,10 & 0,05 & 0,07 & 0,05 & 0,10 & 0,08 \\
\hline $\mathrm{TiO}_{2}$ & 0,03 & 0,01 & 0,01 & 0,01 & 0,01 & 0,01 & 0,03 & 0,01 \\
\hline $\mathrm{P}_{2} \mathrm{O}_{5}$ & 0,02 & 0,04 & 0,02 & 0,03 & 0,03 & 0,02 & 0,04 & 0,03 \\
\hline $\mathrm{MnO}$ & 43,32 & 51,06 & 31,94 & 14,43 & 32,93 & 14,43 & 51,06 & 34,74 \\
\hline A.Z. & 7,50 & 9,00 & 5,60 & 3,00 & 5,40 & 3,00 & 9,00 & 6,10 \\
\hline Toplam & 99,83 & 94,09 & 99,87 & 99,91 & 99,9 & 94,09 & 99,91 & 98,72 \\
\hline $\mathrm{Ni}$ & 223,1 & 268,5 & 222,3 & 158,5 & 223,8 & 158,50 & 268,50 & 219,24 \\
\hline $\mathrm{Co}$ & 525 & 423,9 & 465,2 & 436,9 & 339,1 & 339,10 & 525,00 & 438,02 \\
\hline $\mathrm{Sc}$ & 1 & 1 & 1 & 1 & 1 & 1 & 1 & 1 \\
\hline $\mathrm{Ba}$ & 4543 & 3598 & 3660 & 3031 & 3083 & 3031,00 & 4543,00 & 3583,00 \\
\hline
\end{tabular}


Çizelge 1. (Devam1)

Table 1. (Continuation)

\begin{tabular}{|c|c|c|c|c|c|c|c|c|}
\hline Cs & 0,2 & 0,1 & 0,1 & 0,1 & 0,1 & 0,10 & 0,20 & 0,12 \\
\hline $\mathrm{Ga}$ & 6,7 & 3,4 & 4,4 & 1 & 0,7 & 0,70 & 6,70 & 3,24 \\
\hline $\mathrm{Nb}$ & 0,4 & 0,1 & 0,3 & 0,4 & 0,2 & 0,10 & 0,40 & 0,28 \\
\hline $\mathrm{Rb}$ & 2,7 & 0,2 & 0,3 & 0,1 & 0,3 & 0,10 & 2,70 & 0,72 \\
\hline $\mathrm{Sr}$ & 397,5 & 562,2 & 421,8 & 263,4 & 358,7 & 263,40 & 562,20 & 400,72 \\
\hline $\mathrm{Zr}$ & 30,5 & 14,2 & 19,4 & 13 & 13,5 & 13,00 & 30,50 & 18,12 \\
\hline Hf & 0,4 & 0,2 & 0,1 & 0,1 & 0,1 & 0,10 & 0,40 & 0,18 \\
\hline $\mathrm{Th}$ & 0,6 & 0,2 & 0,2 & 0,2 & 0,2 & 0,20 & 0,60 & 0,28 \\
\hline $\mathrm{U}$ & 1,8 & 4,5 & 2,6 & 1,4 & 3,1 & 1,40 & 4,50 & 2,68 \\
\hline $\mathrm{V}$ & 153 & 244 & 176 & 107 & 160 & 107,00 & 244,00 & 168,00 \\
\hline $\mathrm{Y}$ & 7,3 & 2,4 & 2,4 & 2,1 & 3,2 & 2,10 & 7,30 & 3,48 \\
\hline Mo & 18,2 & 75,4 & 32,8 & 10,7 & 42,9 & 10,70 & 75,40 & 36,00 \\
\hline $\mathrm{Cu}$ & 208,2 & 48,7 & 43,9 & 24,4 & 42,2 & 24,40 & 208,20 & 73,48 \\
\hline $\mathrm{Pb}$ & 24,5 & 7,8 & 9,3 & 6,5 & 4,1 & 4,10 & 24,50 & 10,44 \\
\hline $\mathrm{Zn}$ & 83 & 151 & 93 & 50 & 99 & 50,00 & 151,00 & 95,20 \\
\hline As & 18,3 & 16,3 & 12 & 6,8 & 13,3 & 6,80 & 18,30 & 13,34 \\
\hline $\mathrm{Tl}$ & 4 & 8,1 & 9,3 & 4,4 & 5,7 & 4,00 & 9,30 & 6,30 \\
\hline $\mathrm{La}$ & 11,1 & 3,5 & 3,9 & 3,6 & 4 & 3,50 & 11,10 & 5,22 \\
\hline $\mathrm{Ce}$ & 8,1 & 2,1 & 1,7 & 1,8 & 2,1 & 1,70 & 8,10 & 3,16 \\
\hline $\operatorname{Pr}$ & 1,91 & 0,5 & 0,46 & 0,44 & 0,62 & 0,44 & 1,91 & 0,79 \\
\hline $\mathrm{Nd}$ & 7,5 & 1,9 & 1,9 & 1,9 & 2,5 & 1,90 & 7,50 & 3,14 \\
\hline $\mathrm{Sm}$ & 1,47 & 0,33 & 0,35 & 0,3 & 0,41 & 0,30 & 1,47 & 0,57 \\
\hline $\mathrm{Eu}$ & 0,38 & 0,02 & 0,07 & 0,08 & 0,12 & 0,02 & 0,38 & 0,13 \\
\hline $\mathrm{Gd}$ & 1,4 & 0,51 & 0,45 & 0,46 & 0,54 & 0,45 & 1,40 & 0,67 \\
\hline $\mathrm{Tb}$ & 0,21 & 0,07 & 0,07 & 0,06 & 0,08 & 0,06 & 0,21 & 0,10 \\
\hline Dy & 1,36 & 0,52 & 0,52 & 0,43 & 0,49 & 0,43 & 1,36 & 0,66 \\
\hline Но & 0,26 & 0,14 & 0,11 & 0,11 & 0,11 & 0,11 & 0,26 & 0,15 \\
\hline $\mathrm{Er}$ & 0,86 & 0,41 & 0,39 & 0,32 & 0,41 & 0,32 & 0,86 & 0,48 \\
\hline $\mathrm{Tm}$ & 0,11 & 0,07 & 0,06 & 0,05 & 0,06 & 0,05 & 0,11 & 0,07 \\
\hline $\mathrm{Yb}$ & 0,71 & 0,62 & 0,47 & 0,31 & 0,5 & 0,31 & 0,71 & 0,52 \\
\hline $\mathrm{Lu}$ & 0,11 & 0,09 & 0,09 & 0,05 & 0,08 & 0,05 & 0,11 & 0,08 \\
\hline$\Sigma \mathrm{REE}$ & 35,48 & 10,78 & 10,54 & 9,91 & 12,02 & 9,91 & 35,48 & 15,75 \\
\hline $\mathrm{Mn} / \mathrm{Fe}$ & 40,79 & 111,75 & 60,98 & 26,85 & 60,51 & 26,85 & 111,75 & 60,18 \\
\hline Y/Ho & 28,08 & 17,14 & 21,82 & 19,09 & 29,09 & 17,14 & 29,09 & 23,04 \\
\hline $\mathrm{Co} / \mathrm{Ni}$ & 2,35 & 1,58 & 2,09 & 2,76 & 1,52 & 1,52 & 2,76 & 2,06 \\
\hline $\mathrm{Co} / \mathrm{Zn}$ & 6,33 & 2,81 & 5,00 & 8,74 & 3,43 & 2,81 & 8,74 & 5,26 \\
\hline $\mathrm{Fe} / \mathrm{Ti}$ & 39,00 & 50,00 & 57,00 & 58,00 & 60,00 & 39,00 & 60,00 & 52,80 \\
\hline $\mathrm{Al} /(\mathrm{Al}+\mathrm{Fe})$ & 0,47 & 0,28 & 0,30 & 0,34 & 0,31 & 0,28 & 0,47 & 0,34 \\
\hline $\mathrm{Al} /(\mathrm{Al}+\mathrm{Mn}+\mathrm{Fe})$ & 0,02 & 0,00 & 0,01 & 0,02 & 0,01 & 0,00 & 0,02 & 0,01 \\
\hline $\mathrm{Ce}_{\text {anom, }}$ & $-0,43$ & $-0,49$ & $-0,62$ & $-0,57$ & $-0,57$ & $-0,62$ & $-0,43$ & $-0,54$ \\
\hline $\mathrm{Ce} / \mathrm{Ce}^{*}{ }_{\mathrm{PAAS}}$ & 0,41 & 0,37 & 0,29 & 0,33 & 0,31 & 0,29 & 0,41 & 0,34 \\
\hline $\mathrm{Ce} / \mathrm{Ce}^{*}{ }_{\text {NASC }}$ & 0,41 & 0,37 & 0,29 & 0,33 & 0,31 & 0,29 & 0,41 & 0,34 \\
\hline $\operatorname{Pr}_{\mathrm{PAAS}} / \operatorname{Pr}_{\mathrm{PAAS}} *$ & 1,34 & 1,37 & 1,35 & 1,27 & 1,40 & 1,27 & 1,40 & 1,35 \\
\hline $\mathrm{Eu} / \mathrm{Eu}^{*}{ }_{\mathrm{PAAS}}$ & 1,32 & 0,27 & 0,90 & 1,20 & 1,33 & 0,27 & 1,33 & 1,00 \\
\hline $\mathrm{La}_{\mathrm{PAAS}} / \mathrm{Ce}_{\mathrm{PAAS}}$ & 2,94 & 3,57 & 4,92 & 4,29 & 4,09 & 2,94 & 4,92 & 3,96 \\
\hline $\mathrm{Y}_{\mathrm{PAAS}} / \mathrm{Ho}_{\mathrm{PAAS}}$ & 1,03 & 0,63 & 0,80 & 0,70 & 1,07 & 0,63 & 1,07 & 0,85 \\
\hline$\Sigma \mathrm{REE} / \mathrm{Fe} \times 10^{-4}$ & 43,36 & 30,83 & 26,44 & 24,43 & 28,65 & 24,43 & 43,36 & 30,74 \\
\hline $\mathrm{Ti} / \mathrm{V}$ & 1,18 & 0,25 & 0,34 & 0,56 & 0,37 & 0,25 & 1,18 & 0,54 \\
\hline $\mathrm{Lu}_{\mathrm{PAAS}} / \mathrm{La}_{\mathrm{PAAS}}$ & 0,68 & 1,75 & 1,57 & 0,95 & 1,36 & 0,68 & 1,75 & 1,26 \\
\hline
\end{tabular}




\section{ANALITIKK BULGULAR}

\section{Ana Elementler}

Cihanpaşa (Yozgat) bölgesinden derlenen 5 adet manganez örneğinin jeokimyasal analiz sonuçları Çizelge 1'de verilmiştir (ortalama değerler ile gösterilmiştir). Analiz edilen örnekler, yüksek $\mathrm{MnO} \% 14-51(\sim \% 34,7)$ ve $\mathrm{SiO}_{2} \% 32-81(\sim \% 55,9)$ içeriklerine sahiptir. Her iki element arasında, oldukça güçlü negatif bir ilişki gözlenmektedir $\left(\mathrm{r}_{\mathrm{Mn}}\right.$ $\left.\mathrm{Si}_{\mathrm{i}}=-0.99\right)$. Mn ve Si, çalışılan cevherleşmelerde ana bileşenler olduğundan, ana mineral fazları da bu elementleri yansitacak mineralleden oluşmaktadır. Oksit fazlar çıkartıldığında, toplam Mn (TMn) değeri, \%10,9 ile \%39 ( \% \%26,6) arasında değişmektedir.

İncelenen tüm örnekler önemli oranda düşük $\mathrm{Fe}_{2} \mathrm{O}_{3} \% 0,5-1,1 \quad(\sim 0,68), \mathrm{Al}_{2} \mathrm{O}_{3} \% 0,19$ $1,02(\sim \% 0,4)$ ve $\mathrm{TiO}_{2}(\% 0,01-0,03)$ içeriğine sahiptir. Bu elementlerden alüminyum sedimanter kayaçların kırıntılı fonksiyonu ile ilişkilidir ve depolanma ortamına ilksel kırıntılı katkısını işaret etmektedir (Murray vd., 1992; Ganno vd., 2017). Al ve Ti depolanma ortamına nehirler ile solid partiküllerin taşındığı oldukça düşük çözülebilir özelliğe sahip elementlerdir. Bu şekilde, her iki elementin düşük ya da yüksek olması, depolanma ortamına o kadar kırıntılı fazların az ya da çok giriş yaptığını göstermektedir.

$\mathrm{MgO}(\% 0,06-0,73), \mathrm{CaO} \% 0,21-0,86 \quad(\sim$ $\% 0,47)$ ve toplam alkali $\left(\mathrm{Na}_{2} \mathrm{O}+\mathrm{K}_{2} \mathrm{O}\right) \% 0,06-$ $0,11 \quad(\% 0,09)$ düşük içerikleri, çalışılan cevherleşmelerde silikat minerallerinin oldukça düşük miktarlarda olduğunu ifade etmektedir. Ateşte zayiat değerleri, \%3 ile 7,5 arasında değişmektedir ve $\mathrm{CaO}$ ile ateşte zayiat değerleri arasında gözlenen pozitif anomali $\left(\mathrm{r}_{\mathrm{AZ}-\mathrm{CaO}}=\right.$ 0,91) manganez oksit cevherleşmelerindeki karbonatlı mineral fazları ile ilişskilidir. Çalışılan cevherleşmeler, düşük $\mathrm{P}_{2} \mathrm{O}_{5}$ değerleri $(\% 0,02-$ $0,04)$ içermektedir.

\section{Eser Elementler}

Cihanpaşa (Yozgat) manganez cevherleşmelerinin ana kaya, eser ve nadir yer element içerikleri Çizelge 1'de verilmiştir. Eser elementler ve nadir yer elementleri, PAAS (Post Archean Australian Shale)'e göre normalize edildiğinde, düşük değerler sunmaktadır. Çalışılan manganez cevherleşmelerinin $\mathrm{Ni}$ içerikleri 158-268 ppm, Co içerikleri 339-525 ppm, Ba içerikleri 3.031-4.543 ppm, Sr içerikleri 263-562 ppm arasında değişmektedir. $\mathrm{Co} / \mathrm{Ni}$ oranı ortalama 2,09 ppm, Co/Zn oranı ise ortalama 5,26'dır ve bu değerler Co zenginleşmesinden dolay1 hidrotermal manganez yatakları için literatürde verilen değerlerden yüksektir. Bununla birlikte, bu cevherleşmelerin $\mathrm{Cu}+\mathrm{Co}+\mathrm{Cu}$ içerikleri ortalama 730 ppm'dir ve hidrojenetik yatakların içeriklerinden daha düşüktür. Farklı jenetik tipler ile karşılaştırıldığında, hidrojenetik yataklar düşük $\mathrm{Mn} / \mathrm{Fe}$ oranı $(<1)$, yüksek $\mathrm{Ni}+\mathrm{Cu}(>3.000$ ppm) değerlerine sahiptirler (Bonatti vd., 1972). KB Pasifik'teki hidrojenetik yataklar, yüksek $\mathrm{Ni}+\mathrm{Cu}$ (4.028 ile $6.478 \mathrm{ppm})$ ve düşük $\mathrm{Mn} /$ Fe $(0,81$ ile $1,63 \mathrm{ppm})$ oranına sahiptir (Usui ve Someya 1997). Aynı bölgeden hidrotermal yataklar ile ilgili düşük $\mathrm{Cu}$ (228 ppm), Ni (287 ppm) ve Co (72,3 ppm) element içerikleri Usui ve Someya (1997) tarafından rapor edilmiştir. Çalışılan manganez cevherleşmelerinin düşük $\mathrm{Ni}+\mathrm{Cu}$ değerlerine (182-431 ppm, 292 ppm) ve yüksek Mn/Fe (26-111 ppm, 60,18 ppm) oranına sahip olması hidrotermal yatakların değerleri ile uyum sağlamaktadır. Yüksek Co, Ce ve Tl içerikleri, hidrojenetik kabukların oldukça yavaş soğurma ve oksidasyon işlemleri ile oluştuğunu gösteren hidrojenetik oksihidroksit materyallerin en tipik özelliklerden biridir (Dubinin vd., 2008). Cihanpaşa manganez cevherleşmelerinin Co $(\sim 438$ ppm), düşük Ce $(\sim 3,2$ ppm) ve Tl ( 6,3 ppm) içerikleri bu oluşumların hidrojenetik oluşumlar ile ilişkili olmadığını, aksine hidrotermal kökenli manganez cevherleşmelerine benzerlik gösterdiğini ifade etmektedir. 
Y/Ho oranı manganez oluşumlarında ortamın yorumlanmasina kullanılabilmektedir. Lan vd. (2019)'ye göre, bu oranın 26'dan yüksek olması kırıntılı getirimi ile kirlenmenin egemen olduğunu göstermektedir. Cihanpaşa manganez oluşumlarının Y/Ho oranı ortalama 23 olması kirlenmeden etkilenmediğini ya da kısmen etkilendiğini göstermektedir (Çizelge 1). Kırıntılı getiriminin egemen olup olmadığını ortaya koymak için $\mathrm{Zr}$ ile Y/Ho oranlarının korelasyonu güçlü bilgi verebilmektedir. Cihanpaşa $\mathrm{Mn}$ cevherleşmelerinin $\mathrm{Zr}$-Y/Ho arasındaki pozitif ilişkinin $(0,48)$ güçlü olmaması, ortama kırıntılı getiriminin kısmi olduğunu göstermektedir.

\section{Nadir Yer Elementleri}

Hidrojenetik yataklar $(>1.000 \quad$ ppm $)$ ile karşılaştırıldığında, hidrotermal yataklar düşük $\Sigma$ NYE içeriklerine ( $<100 \mathrm{ppm})$ sahiptir. Cihanpaşa Mn cevherleşmelerinin $\Sigma$ NYE içerikleri 9,9135,48 ppm $(\sim 15,75 \mathrm{ppm})$ arasında değişmektedir ve düşük $\Sigma$ NYE içerikleri, hidrotermal yataklar için uyumludur. Diyajenetik-tip manganez yatakları $\mathrm{Mn} / \mathrm{Fe}$ oranı $(>2,5)$, yüksek $\mathrm{Cu}-$ $\mathrm{Ni}$ ve düşük Co değerleri göstermektedir (Hein ve Koschinsky, 2014). Cihanpaşa Mn cevherleşmeleri PAAS'a göre normalize edildiğinde, negatif $\mathrm{Ce}$ anomalisi, hafif negatif ve pozitif Eu anomalisi göstermektedir (Şekil 4). Cihanpaşa Mn cevherleşmeleri, ağır nadir toprak elementlerine göre hafif nadir toprak elementleri ve orta nadir toprak elementlerinin fakirleşmesi ile karakteristik özelliklere sahiptir $\left(\mathrm{Gd}_{\text {PAAS }} / \mathrm{Yb}_{\text {PAAS }}<1\right.$ $\left.(\sim 0,76) ; \mathrm{La}_{\text {PAAS }} / \mathrm{Yb}_{\text {PAAS }}<1 \quad(\sim 0,73)\right)$. Çalışılmış cevherleşmeler, düşük sicaklıklı hidrotermal yataklara benzer olarak negatif Ce ve 1,12 ile 1,36 arasında değişen pozitif Gd anomalisi sunmaktadır ve düşük sıcaklık hidrotermal sıvılara benzerlik göstermektedir. Şekil 4'te gösterildiği gibi, EPR ve MAR yüksek sıcaklık hidrotermal sıvılar oldukça güçlü Eu anomalisi ve pozitif $\mathrm{Y} / \mathrm{Y}^{*}$ anomalisi sunmaktadır. Oksijen bakımından zengin modern deniz suyu önemli negatif Ce anomalisi, pozitif La, Y, Gd sunarken (Şekil 4), yarı oksik ve anoksik sular negatif $\mathrm{Ce}$ anomalisinden yoksundurlar (German ve Elderfield 1990). Cihanpaşa Mn cevherleşmeleri, pozitif La ve negatif Ce anomalisi ile modern deniz suyuna ve hidrotermal yatakların nadir toprak element desenlerine benzerlik göstermektedir. Cevherleşmelerde gözlenen negatif Ce anomalisinin gerçek olup olmadığını test etmek için $\mathrm{Ce}_{\mathrm{PAAS}} / \mathrm{Ce}_{\mathrm{PAAS}}$ * $-\operatorname{Pr}_{\mathrm{PAAS}} / \operatorname{Pr}_{\mathrm{PAAS}}$ * diyagramı kullanılmıştır (Bau vd., 1996; 1997). Bu diyagrama göre, Cihanpaşa Mn cevherleşmeleri gerçek negatif Ce anomalisi alanına düşmektedir (Şekil 5).

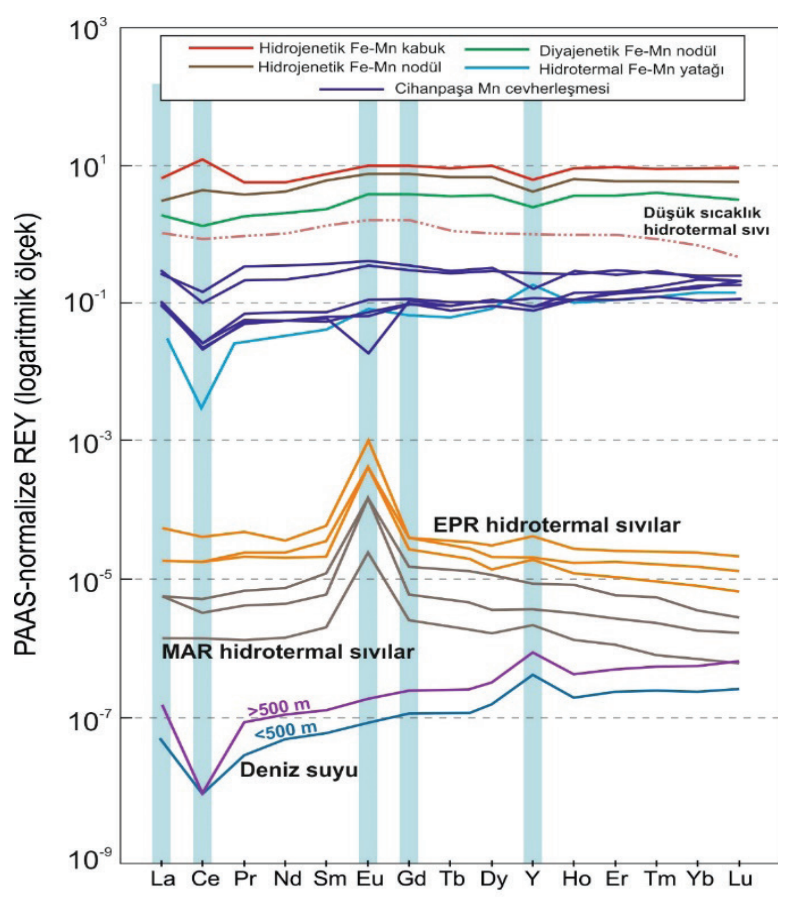

Şekil 4. PAAS (Post-Archean Australian shale)normalize edilmiş NYE desenleri (McLennan, 1989). Düşük sıcaklık hidrotermal sıvı, hidrojenetik FeMn kabuk, nodüller, diyajenetik Fe-Mn nodül ve hidrotermal Fe-Mn yatağı verileri (Bau ve Dulski, 1999)'den alınmıştır. Doğu Pasifik Sırtı (EPR) hidrotermal sivilar (Douville vd., 1999); Atlantik Ortası Sirtı (MAR) hidrotermal sıvılar (Bau ve Dulski, 1999); ortalama deniz suyu ( $>500 \mathrm{ve}<500 \mathrm{~m}$ derinlik) (Alibo ve Nozaki, 1999). 
Figure 4. PAAS (Post-Archean Australian shale)normalized REE patterns (normalized after McLennan, 1989). The low-temperature hydrothermal fluid, hydrogenetic Fe-Mn crust, nodules, diagenetic Fe-Mn nodule and hydrothermal $\mathrm{Fe}-\mathrm{Mn}$ deposit are adapted from Bau and Dulski (1999). Data on East Pacific Ridge (EPR) hydrothermal fluids (Douville et al., 1999); hydrothermal fluids from the Mid-Atlantic Ridge (MAR) (Bau and Dulski, 1999); and average seawater (>500 and $<500 \mathrm{~m}$ depth, Alibo and Nozaki, 1999) taken from named sources.

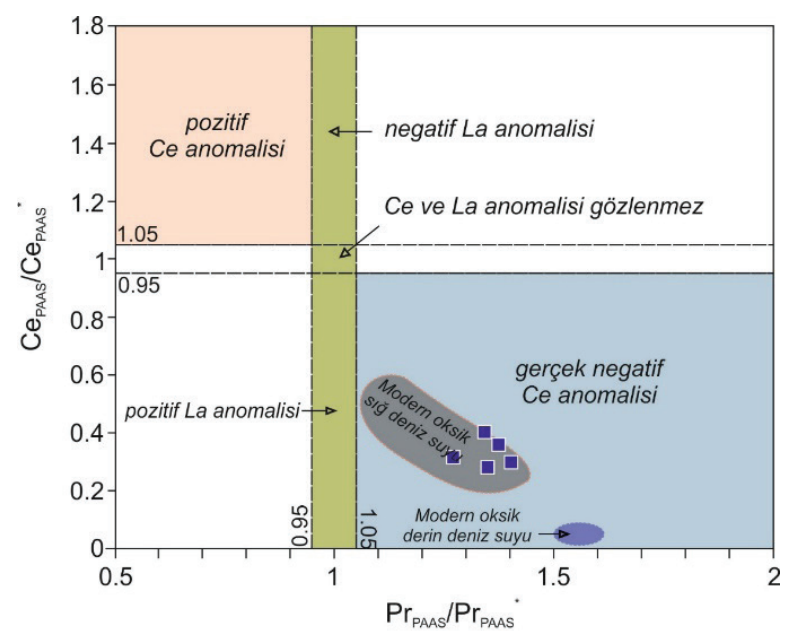

Şekil 5. Ce ve $\mathrm{La}$ anomalileri için $\mathrm{Ce}_{\mathrm{PAAS}} / \mathrm{Ce}_{\mathrm{PAAS}}$ * $-\mathrm{Pr}_{\mathrm{PAAS}} / \mathrm{Pr}_{\mathrm{PAAS}}$ * ayırım diyagramı (Bau ve Dulski, 1999). Cihanpaşa manganez cevherleşmelerine ait tüm örnekler oksik depolanma ortamını ifade eden gerçek Ce anomalileri göstermektedir ve modern oksik sığ deniz suyu alanına düşmektedir. Modern derin deniz suyu Alibo ve Nozaki (1999) ve sığ oksik deniz suyu Nothdurft vd. (2004)'den alınmıştır.

Figure 5. $C e_{P A A S} / C e_{P A A S} * v S \operatorname{Pr}_{P A A S} / P r_{P A A S}$ * discrimination diagram for Ce and La anomalies (Bau and Dulski, 1996). Note that all analyzed samples of the Cihanpassa $\mathrm{Fe}-\mathrm{Mn}$ ores display true negative $\mathrm{Ce}$ anomalies, indicative of oxic conditions, and plot within the field of modern oxic shallow water. The fields for modern deep and shallow oxic seawater are from Alibo and Nozaki (1999) and Nothdurft et al. (2004), respectively.

\section{TARTIŞMA}

Manganez oksit yatakları deniz suyundan kimyasal ve sedimanter işlemler ile çökelim yaparak oluşurlar ve farklı tipler altında incelenmektedirler. Bunlardan, hidrotermaltip manganez oksit yatakları, farklı jeotektonik ortamlarda (denizaltı yayılma merkezlerinde, plaka içi deniz dağlarında, ada yaylarında) oluşan düşük sıcaklık hidrotermal solüsyonların çökelimi ile oluşmaktadır (Roy, 1997; Fitzgerald ve Gillis, 2006). Bu yatakların oluşumunda, sedimanter ortamdaki hidrotermal etkinliğin ve bu ortama volkanik etkinin olup olmadığını ortaya koymak önemlidir. Al ve Ti elementleri, kökeni ortaya koymak ve yorumlamak için kullanılmaktadır (Crerar vd., 1982). Al, genellikle kil içeriği bakımından zengin kayaçlarda zenginleşmektedir ve bu elementin yüksek değerleri mangan çökelimi süresince ortama sedimanter bir katkının olup olmadığını ifade etmektedir (Maynard, 2010). Ti, hidrotermal solüsyonlarda durayl1 bir element olarak düşünülmektedir (Sugisaki, 1984). Manganez yataklarının kökenini ortaya koymada, her iki elementin düşük değerleri ortama kırıntılı malzeme girişi ile çok az katkının olduğunu göstermektedir. $\mathrm{Al}_{2} \mathrm{O}_{3} / \mathrm{TiO}_{2}$ oran1, ayrışma, sedimanter taşınım ya da diyajenez gibi olayların aksine (Hayashi vd., 1997; Sugitani vd., 1996), volkanik etki ile etkilenmektedir (Gao vd., 2018). İzmir-Ankara-Erzincan okyanusunun okyanusal kabuğundan şekillenmiş olan farklı tip mafik volkanik kayaçların (N-MORB, E-MORB, OIB, SSZ) $\mathrm{Al}_{2} \mathrm{O}_{3} / \mathrm{TiO}_{2}$ oran1 8 ile 18 arasinda değişmektedir (Aldanmaz vd., 2008). Cihanpaşa manganez cevherleşmelerinin $\mathrm{Al}_{2} \mathrm{O}_{3} / \mathrm{TiO}_{2}$ oran 19-34 arasında ( 27) arasında değişmektedir ve mafik volkanik kayaçlardan daha yüksek $\mathrm{Al}_{2} \mathrm{O}_{3} /$ $\mathrm{TiO}_{2}$ değerlerine sahip olması, cevherleşmelerin volkanik faaliyetlerinden etkilenmediğini göstermektedir. Buna ek olarak, çalışılan cevherleşmelerin $\mathrm{Al}_{2} \mathrm{O}_{3} / \mathrm{TiO}_{2}$ oranları, Fanerozoyik sedimanter kayaçların (Condie 1993; Hayashi vd., 1997; Sugitani vd., 1996) değerleri arasında (2030) yer alması, bu görüşü desteklemektedir. 
Diğer taraftan, bazı denizel Fe-Mn kabuklarda Ga zenginleşmeleri literatürde rapor edilmektedir. Örneğin; Sakhno (2008), Belyaevsky Seamount (Japon Denizi)'daki ferromanganez kabuk oluşumlarının 300 ppm'e kadar Ga zenginleşmelerine sahip olduğunu ve yüksek Ga içeriklerinin sedimanter çökelim ortamına volkanik kül materyallerin taşınması ile ilişkili olduğunu ortaya koymuştur. Cihanpaşa Mn cevherleşmelerinin düşük Ga değerleri 0,7$6,7(\sim 3,2)$, bu cevherleşmelerin oluşumlarında volkanik etkinin olmadığını gösteren verilerden biridir. İnceleme alanına yakın bölgede bulunan Eymir (Yozgat, İç Anadolu) manganez cevherleşmeleri, yüksek Ga içeriklerine ( $\sim 89,15$ ppm) sahiptir (Öksüz, 2011a). Batı Anadolu'da Kula bölgesi Mn cevherleşmelerinin yüksek Ga değerlerine $(\sim 51,17)$ sahip olmas1, bu cevherleşmelerin oluşumlarında felsik volkanik materyalin etkin olduğunu göstermektedir ki bu volkanik materyaller radyolaryalı çörtler ile birlikte Kula (Manisa) bölgesinde gözlenebilmektedir (Kılıç vd., 2008).

Cihanpaşa manganez cevherleşmelerinin kökenini ortaya koymak amaciyla literatürden bazı diyagramlardan yararlanılmıştır. $\mathrm{Bu}$ diyagramlardan, $\mathrm{SiO}_{2}-\mathrm{Al}_{2} \mathrm{O}_{3}$ diyagram1, mangan içeren sedimanter kayaların kökenini ortaya koymaktadır (Bonatti, 1975). Bu diyagramda, Cihanpaşa cevherleşmeleri hidrotermal depolanma alanı içerisinde toplanmaktadır (Şekil 6a). Si/Al oranı hidrojenetik, hidrotermal, kırıntılı materyallerin kökeninin aydınlatması açısından önemlidir (Crear vd., 1982). Yüksek Si/Al oranı hidrotermal getirimi desteklerken, düşük $\mathrm{Si}$ / Al oranı kırıntılı materyaller ile karışmış bir hidrotermal kökeni ifade etmektedir (Holtstam ve Mansfield, 2001). Hidrojenetik ferromanganez nodüllerde $\mathrm{Si} / \mathrm{Al}$ oranı yaklaşık 3 civarındayken, ferromanganez kabuklarda 5,1 ve Fe-zengini hidrotermal kabuklarda bu oran oldukça yüksektir ve 600-900 arasında değişmektedir (Alvi ve Shaif, 2020). Çalışılan cevherleşmelerde yüksek Si/Al oranı ( 190), hidrotermal getirimi desteklemektedir. Diğer taraftan, hidrojenetik yataklar ile karşılaştırıldığında, hidrotermal yataklar düşük Co ve $\mathrm{Ni}$ içeriklerine sahiptir. Böylece, her iki kökeni birbirinden ayıran (Co + $\mathrm{Ni})-(\mathrm{As}+\mathrm{Cu}+\mathrm{Mo}+\mathrm{Pb}+\mathrm{V}+\mathrm{Zn}$ ) diyagramında Cihanpaşa Mn-cevher örnekleri düşük Co ve $\mathrm{Ni}$ içeriklerine sahiptir ve hidrotermal alana düşmektedir (Şekil 6b). Bonatti vd. (1972) tarafından geliştirilen $\mathrm{Fe}-\mathrm{Mn}-(\mathrm{Ni}+\mathrm{Co}+\mathrm{Cu}) \quad \mathrm{x}$ 10 üçgen diyagramında, çalışılan manganez cevherleşmeleri hidrotermal yataklar alanına düşmektedir (Şekil 6c). Buna ek olarak, klasik diyagramların haricinde son zamanlarda Josso vd. (2017) tarafindan geliştirilen $(\mathrm{Mn}+\mathrm{Fe}) / 4$ $100 *(\mathrm{Zr}+\mathrm{Ce}+\mathrm{Y})-15 *(\mathrm{Cu}+\mathrm{Ni})$ üçgen diyagramda da aynı şekilde cevherleşmeler hidrotermal köken alanında toplanmaktadır (Şekil 6d). Benzer şekilde, Bau vd. (2014) tarafindan $\mathrm{Y}_{\mathrm{PAAS}} / \mathrm{Ho}_{\mathrm{PAAS}}{ }^{-}$ $\mathrm{Nd}$ (Şekil 6e) diyagramında cevher örnekleri hidrotermal alana düşerken, $\mathrm{Ce}_{\mathrm{PAAS}} / \mathrm{Ce}_{\mathrm{PAAS}}$ *$\mathrm{Y}_{\text {PAAS }} / \mathrm{Ho}_{\text {PAAS }}$ (Şekil 6f) diyagramında kısmen hidrotermal alana düşmektedir. Bu diyagramda, Bau vd. (2014)'e göre, hidrotermal yataklar pozitif $\mathrm{Y}$ anomalisi ve negatif $\mathrm{Ce}$ anomalisi sunarken, hidrojenetik yataklar pozitif Ce anomalisi ve negatif $\mathrm{Y}$ anomalisi sunmaktadır. Diyajenetik yataklar ise negatif Ce ve $\mathrm{Y}$ anomalisi ile tipiktir.

Önceki okyanus ortamlarının depolanma koşullarını anlayabilmek için redoks element göstergeleri paleocoğrafyanın doğru bir şekilde ifade edilmesinde kullanılmaktadır. Naeher vd. (2013)'e göre, Fe ve Mn bir sedimanter ortamda belirli redoks davranış göstermektedir. Demirin oksidasyonu mangandan daha hızlıdır ve mangan demir ile karşılaştırıldığında yüksek redoks dinamiklerine sahiptir (Engstrom ve Wright, 1984). Böylece, sedimanter ortamın redoks özelliklerini ortaya koymada $\mathrm{Fe} / \mathrm{Mn}$ oranı güçlü ipuçları ortaya koyabilmektedir. Sedimanter ortam okside veya indirgen olduğu zaman, $\mathrm{Fe}$ ve Mn birlikte depolanma eğilimi gösterebilmektedir. Ancak, sedimanter ortam orta derecede okside olduğunda, 
her iki element birbirinden ayrilabilmektedir (Zhu vd., 2013; Gao vd., 2018). Bu nedenle, farkl1 jenetik tiplere ait oluşumların (manganez yatakları veya ferromanganez kabukları) Fe/Mn oran1, bu
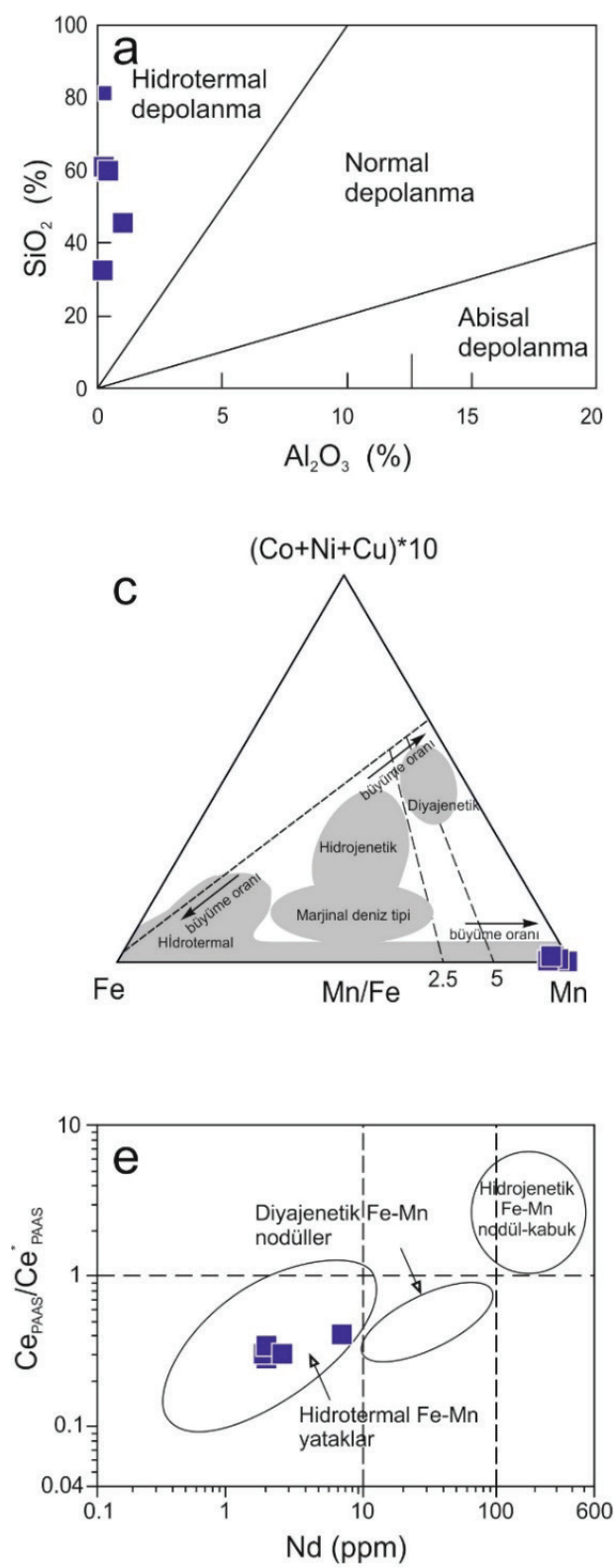

oluşumların redoks özelliklerini ortaya koymak için kullanılabilmektedir (Lu vd., 2006; Zhang vd., 2013).
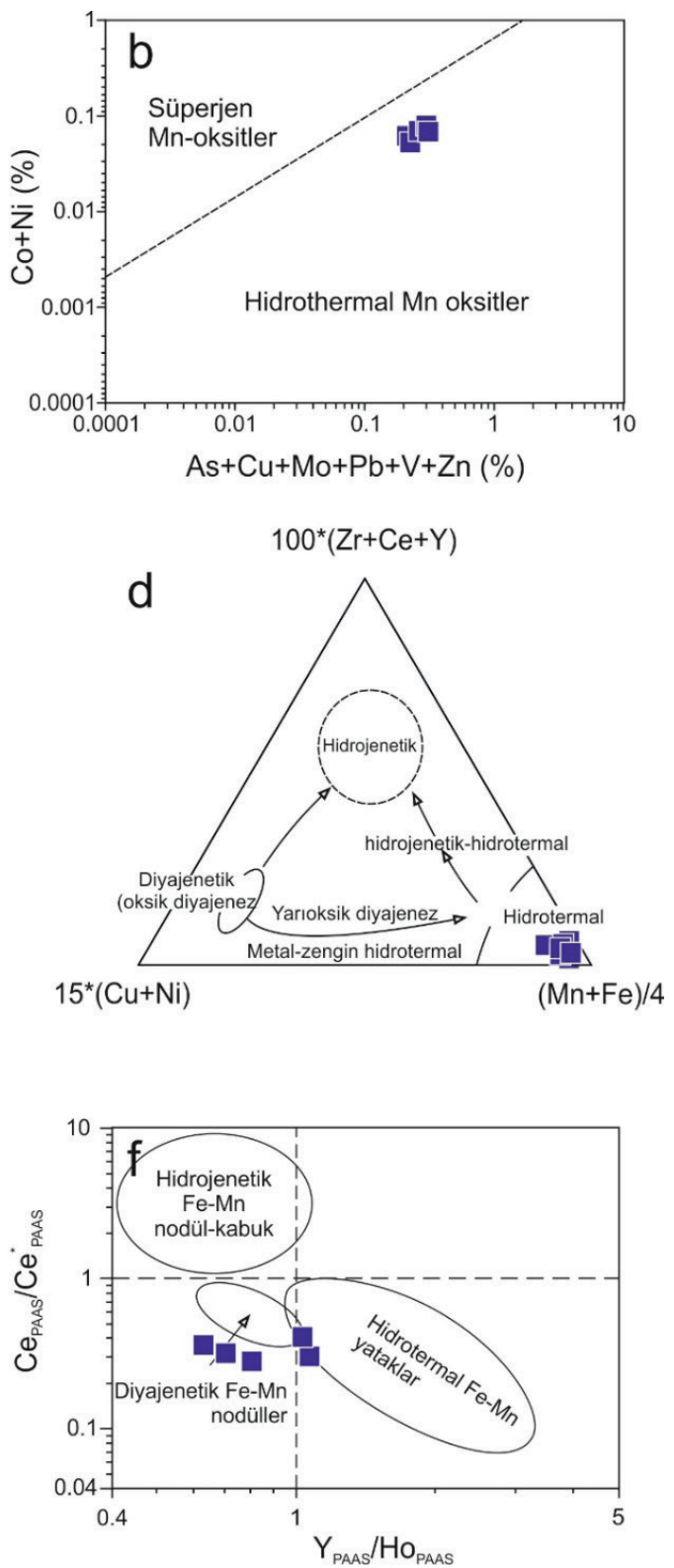

Şekil 6. Cihanpaşa manganez cevherleşmelerinin hidrotermal bileşimlerini ayıran üçgen ve iki değişkenli diyagramları. a) Hidrotermal, normal ve abisal depolanma ortamını gösteren $\mathrm{SiO}_{2}-\mathrm{Al}_{2} \mathrm{O}_{3}$ diyagramı (Toth, 1980; Wonder vd., 1988). b) Süperjen ve hidrotermal Mn-oksitlerin alanlarını ayıran diyagram (Nicholson, 1992). c) Ferromanganez yatakların jenetik modelleri için $(\mathrm{Co}+\mathrm{Ni}+\mathrm{Cu}) * 10-\mathrm{Fe}-\mathrm{Mn}$ üçgen diyagram (Bonatti vd., 1972). Tüm datalar \% şeklinde çizilmiştir. d) Majör (Fe, Mn), eser (Cu ve Ni), ve HFS ve NYE ( $\mathrm{Zr}$, Y, Ce) içerikleri temelinde hazırlanmış üçgen diyagram. e) Cihanpaşa manganez cevherleşmelerinin kökeni için $\left.\mathrm{Ce}_{\mathrm{PAAS}} / \mathrm{Ce}_{\mathrm{PAAS}}{ }^{*}\right)$ 
anomalisi- $\mathrm{Nd}$, ve f) $\mathrm{Ce}_{\mathrm{PAAS}} / \mathrm{Ce}_{\mathrm{PAAS}} *-\mathrm{Y}_{\mathrm{PAAS}} / \mathrm{Ho}_{\mathrm{PAAS}}(\mathrm{Bau}$ vd., 2014) diyagramı.

Figure 6. Triangular and bivariate diagrams discriminating the hydrothermal components of the Cihanpaşa manganese mineralizations. a) $\mathrm{SiO}_{2}$ vs. $\mathrm{Al}_{2} \mathrm{O}_{3}$ plot showing fields of hydrothermal, normal, and abyssal deposition (Toth, 1980; Wonder et al., 1988). b) Diagnostic plot discriminating fields of supergene and hydrothermal Mn-oxides (Nicholson, 1992). c) $(\mathrm{Co}+\mathrm{Ni}+\mathrm{Cu}) * 10-\mathrm{Fe}-\mathrm{Mn}$ ternary diagram for genetic models of ferromanganese deposits, adapted from Bonatti et al. (1972). All data plotted as wt.\%. d) Ternary discriminative diagram on the basis of the concentration of major ( $\mathrm{Fe}$ and $\mathrm{Mn}$ ), trace (Cu and $\mathrm{Ni}$ ), and HFS and REEs (Zr, Y, Ce) (Josso et al., 2017). e) Plot of $\left(C e_{P A A S} / C e_{P A A S} *\right)$ anomaly vs $N d$ concentrations. f) $C e_{P A A S} / C e_{P A A S}^{*}$ vis $Y_{P A A S} / H o_{P A A S}$ diagrams (Bau et al., 2014) for origin of Cihanpaşa manganese mineralizations.

Cihanpaşa Mn cevherleşmelerinde 0,010,07 arasında $(\sim 0,02)$ değişen düşük $\mathrm{Fe} /$ Mn oranları, bu cevherleşmelerin okside bir sedimanter ortamda oluştuğunu göstermektedir. Depolanma ortamlarının redoks özelliklerini belirleyen diğer bir parametre $\mathrm{Ce}$ anomalisidir $\left(\mathrm{Ce}_{\text {anom }}\right.$; Wright vd. (1987) $\left(\left[\mathrm{Ce}_{\text {anom. }}=[\log (3\right.\right.$ $\left.\times \mathrm{Ce}_{\text {örnek }} / \mathrm{Ce}_{\text {seyl }}\left(2 \times \mathrm{La}_{\text {örnek }} / \mathrm{La}_{\text {seyy }}\right)+\left(\mathrm{Nd}_{\text {örnek }} / \mathrm{Nd}_{\text {seyl }}\right)\right]$. Şeyl (Post-Archean Average Australian Shale, Taylor ve Mclennan, 1985). Bu parametreye göre, $\mathrm{Ce}_{\text {anom. }}>-0,1$ ise, sedimanter depolanma ortamında Mn cevherleşmelerinin oluştuğu veya depolandığg ortamdaki suyun oksijen bakımından yetersiz olduğunu, $\mathrm{Ce}_{\text {anom. }}<-0,1$ ise ortamdaki sedimanter suyun oksijen bakımından zengin olduğunu göstermektedir. Cihanpaşa Mn cevherleşmelerinin $\mathrm{Ce}_{\text {anom. }}$ değerleri $-0,43$ ile $-0,67$ arasında değişmektedir ve ortalama $-0,54$ ile bu oluşumların oksijen bakımından zengin bir ortamda ve düşük $\mathrm{Nd}$ değerleri temelinde hızlı çökelim ile oluştuğunu ifade etmektedir (Şekil 7a). Bazı eser elementler (Ni, Cr, V, Mo, Cd, Th, $\mathrm{U})$ redoks şartlarını belirlemede işaretleyicidir (Morford ve Emerson, 1999). Bu elementlerin birbirine göre oranları (Ni/Co, V/(V+Ni), V/Ni,
V/Mo) paleoredoks durumları ortaya koymak için kullanılabilmektedir (Hatch ve Leventhal, 1992; Jones ve Manning, 1994). Bu indislerden, V/ $(\mathrm{V}+\mathrm{Ni})$ oran1 0,54-0,82 arasında anoksik ortam1, 0,46-0,60 arasinda disoksik ve $<0,46$ ise oksik depolanma ortamını ifade etmektedir. Cihanpaşa $\mathrm{Mn}$ cevherleşmelerinin $\mathrm{V} /(\mathrm{V}+\mathrm{Ni})$ oran değerleri 0,40-0,48 ( 0,43) ile oksik depolanma ortamını ifade etmektedir. Buna ek olarak, Ni/Co değerleri 5 'ten küçük ise oksik, 5 ile 7 arasında ise yarı oksik ve 7'den büyük ise anoksik ortam koşullarını göstermektedir. 0,42-0,66 arasında değişen Ni/Co oranları ile Cihanpaşa Mn cevherleşmeleri, oksijen bakımından zengin bir depolanma ortamında oluşmuştur. V/(V+Ni)-Ni/Co diyagramı Cihanpaşa $\mathrm{Mn}$ cevherleşmelerinin oksijenli bir ortamda depolandığını göstermektedir (Şekil 7b). V/Ni oranı anoksik ortamda çökelim yapan sedimanter kayaçlarda 3'ten büyük, yarı oksik ortamlarda 1,9-3 arasında, oksik depolanma ortamlarında ise bu değer 1,9'da küçüktür (Galarraga vd., 2008). Buna göre, cevherleşmelerin $\mathrm{V} / \mathrm{Ni}$ oranı 0,68 0,91 arasında $(\sim 0,76)$ değişmektedir ve bölgedeki manganez cevherleşmelerinin oksik ortamda depolandığını göstermektedir. Gallego-Torres vd., (2010)'e göre, V/Mo oranı depolanma ortamının redoks özellikleri hakkında bilgi vermektedir. $\mathrm{V} / \mathrm{Mo}<2$ ise anoksik, bu oran 2 ile 10 arasında ise yarı oksik ortam koşullarını ve yüksek V/ Mo oranı (10-60) ise oksik ortamda depolanan sedimentleri göstermektedir. Cihanpaşa Mn cevherleşmelerinin V/Mo oran değerleri 3,24-10 arasında değişmektedir ve ortalama V/Mo değeri $6,15^{\prime}$ dir. Bu değerler, yarı oksijenli bir depolanma ortamını ifade etmektedir. Diğer bir parametre, uranyum ile ilişkili kırıntılı fazlar için toryumun düzeltme şeklinde kullanıldığ $\mathrm{U}_{\text {aut }}\left(\mathrm{U}_{\text {aut }}=\mathrm{U}_{\text {total }}{ }^{-}\right.$ $(\mathrm{Th} / 3)$ değeri $5<$ ise oksik ortamı, $>5$ ise anoksik ortamı ifade etmektedir (Wignall ve Myers, 1988). Cihanpaşa $\mathrm{Mn}$ cevherleşmelerinin $\mathrm{U}_{\text {aut }}$ değeri 1,33-4,43 ( 2,59) ile oksik depolanma ortamını işaret etmektedir. 

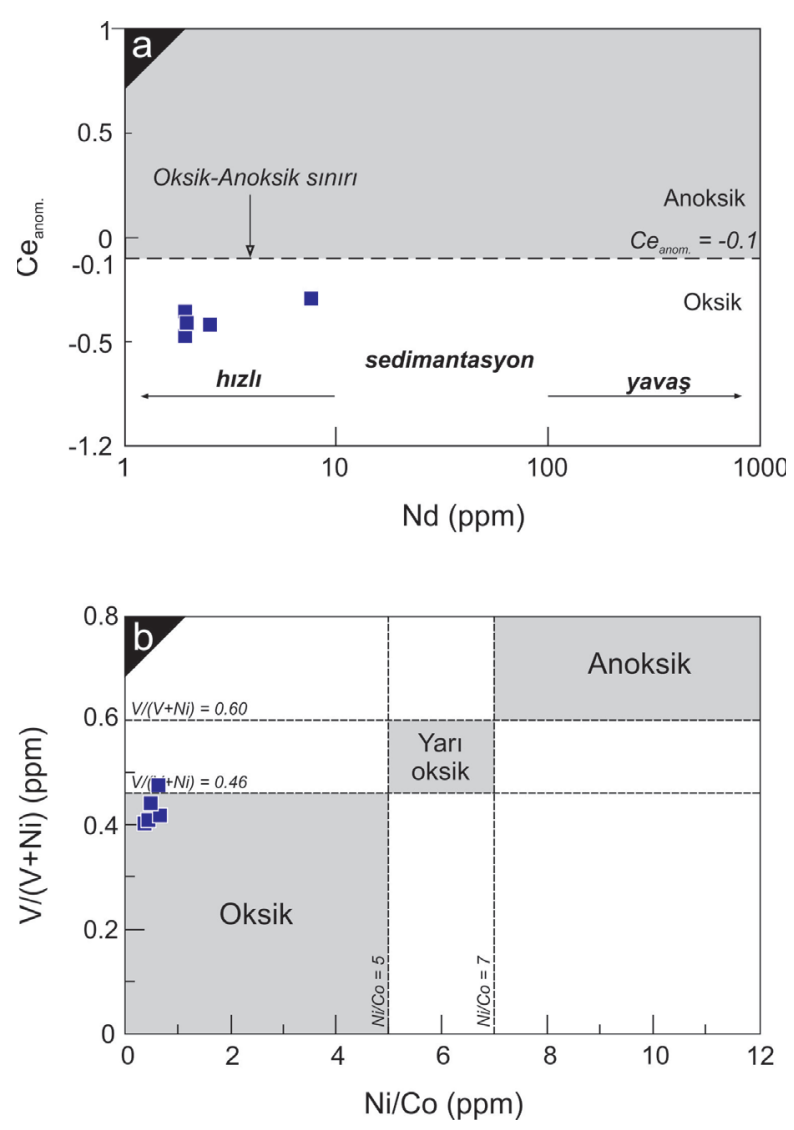

Şekil 7. Oksik, yarı oksik, anoksik ile redoks koşulları gösteren a) $\mathrm{Ce}_{\text {anom. }}-\mathrm{Nd}(\mathrm{ppm})$ ve b) $\mathrm{V} /(\mathrm{V}+\mathrm{Ni})-\mathrm{Ni} / \mathrm{Co}$ diyagramı (Wright vd., 1987; Hatch ve Leventhal, 1992; Jones ve Manning, 1994)

Figure 7. a) $\mathrm{Ce}_{\text {anom }} v \mathrm{~s} . \mathrm{Nd}$, and b) $\mathrm{V} /(\mathrm{V}+\mathrm{Ni})$ vs $\mathrm{Ni} / \mathrm{Co}$ diagrams showing redox conditions as oxic, dysoxic, and anoxic environments (Wright et al., 1987; Hatch and Leventhal, 1992; Jones and Manning, 1994).

Denizel sedimanter çökelimler ile oluşan manganez oluşumlarında, depolanma ortamı 3 farklı alan bazında incelenmektedir: 1) Yayılma sırtına yakın ortamlar, 2) Pelajik (açık okyanus) ortam, 3) Kitasal kenar ortamı (Murray vd., 1990). Çört, radyolaryalı çört, şeyl ve/veya bu birimler ile ilişkili olan manganez oluşumlarının depolanma ortamlarını yorumlayabilmek amaciyla jeokimyasal olarak farklı element oranlı parametrelerden yararlanılmaktadır. $\mathrm{MnO} /$ $\mathrm{TiO}_{2}$ oranı okyanusal fasiyesleri gösteren bir indikatördür (Sugisakivd., 1982; Kunimaru vd., 1998). $\mathrm{MnO} / \mathrm{TiO}_{2}$ oran1 < 0,5 kitasal kenar sedimantasyon ortamın1, $>0,5$ ise pelajik ortam 1 göstermektedir. Cihanpaşa Mn cevherleşmelerinin $\mathrm{MnO} / \mathrm{TiO}_{2}$ oranı ortalama 2,862 ile açık okyanus (pelajik) ortamı işaret etmektedir. $\mathrm{Al}_{2} \mathrm{O}_{3} /\left(\mathrm{Al}_{2} \mathrm{O}_{3}+\right.$ $\mathrm{Fe}_{2} \mathrm{O}_{3}$ ) oranı 0,35 'den küçük ise yayılma sırtına yakın ortamı, 0,35-0,70 ise pelajik (açık okyanus) ortamını ve 0,55-0,90 ise k1tasal kenar ortamını ifade etmektedir. Çalışılan Mn cevherleşmeleri 0,28-0,47 arasında değișen, ortalama 0,34 ile yayılma sirtı ile pelajik ortam arasında kalan bir lokasyonu göstermektedir. Buna ek olarak, çörtlerin depolanma ortamını ortaya koymak amaciyla kullanilan $\left(\mathrm{La}_{\mathrm{SN}} / \mathrm{Ce}_{\mathrm{SN}}\right)-\mathrm{Al}_{2} \mathrm{O}_{3} /\left(\mathrm{Al}_{2} \mathrm{O}_{3}\right.$ $\left.+\mathrm{Fe}_{2} \mathrm{O}_{3}\right)$ ve $\mathrm{Fe}_{2} \mathrm{O}_{3}-\mathrm{Al}_{2} \mathrm{O}_{3} /\left(\mathrm{Al}_{2} \mathrm{O}_{3}+\mathrm{Fe}_{2} \mathrm{O}_{3}\right)$ diagramlarında (Murray vd., 1990) (Şekil 8 a ve b), Cihanpaşa örneklerinin sırt kısmına yakın alanda toplandığ1 gözlenebilmektedir.

$\mathrm{Ti} / \mathrm{V}$ ve V/Y oranları depolanma ortamlarında kullanılan oldukça yararlı göstergelerdir. Bunlardan, Ti/V oran $1 \geq 40$ ve $\mathrm{V} / \mathrm{Y} \leq 2 \mathrm{k}$ tasal kenar ortamlarını işaret etmektedir. Bununla birlikte $\mathrm{Ti} / \mathrm{V} \leq 7$ ve $\mathrm{V} / \mathrm{Y} \geq 2$ yayılma sırtına yakın depolanma ortamları işaret etmektedir (Murray vd., 1991; Li 2000; Kang vd., 2011; Kemkin ve Kemkina, 2020). Pelajik ortam, 7 ile 40 arasında değişen Ti/V değerine sahiptir. Cihanpaşa Mn cevherleşmelerinin $\mathrm{Ti} / \mathrm{V}$ oran 10,25 ile 1,18 $(\sim 0,54)$ arasında değişmektedir (Şekil $8 \mathrm{c}) . \mathrm{V} / \mathrm{Y}$ oran1 ise 20,96 ile 101,67 arasında $(\sim 59,38)$ oldukça geniş aralık sunmaktadır. Diğer taraftan, Cihanpaşa manganez cevherleşmelerinin $\mathrm{Lu}_{\mathrm{SN}}$ / $\mathrm{La}_{\mathrm{SN}}$ oran1 0,68 ile $1,75(\sim 1,26)$ ile yayılma sirtına yakın ortamlara karşıllı gelmektedir (Şekil 8d, Murray vd., 1991). 

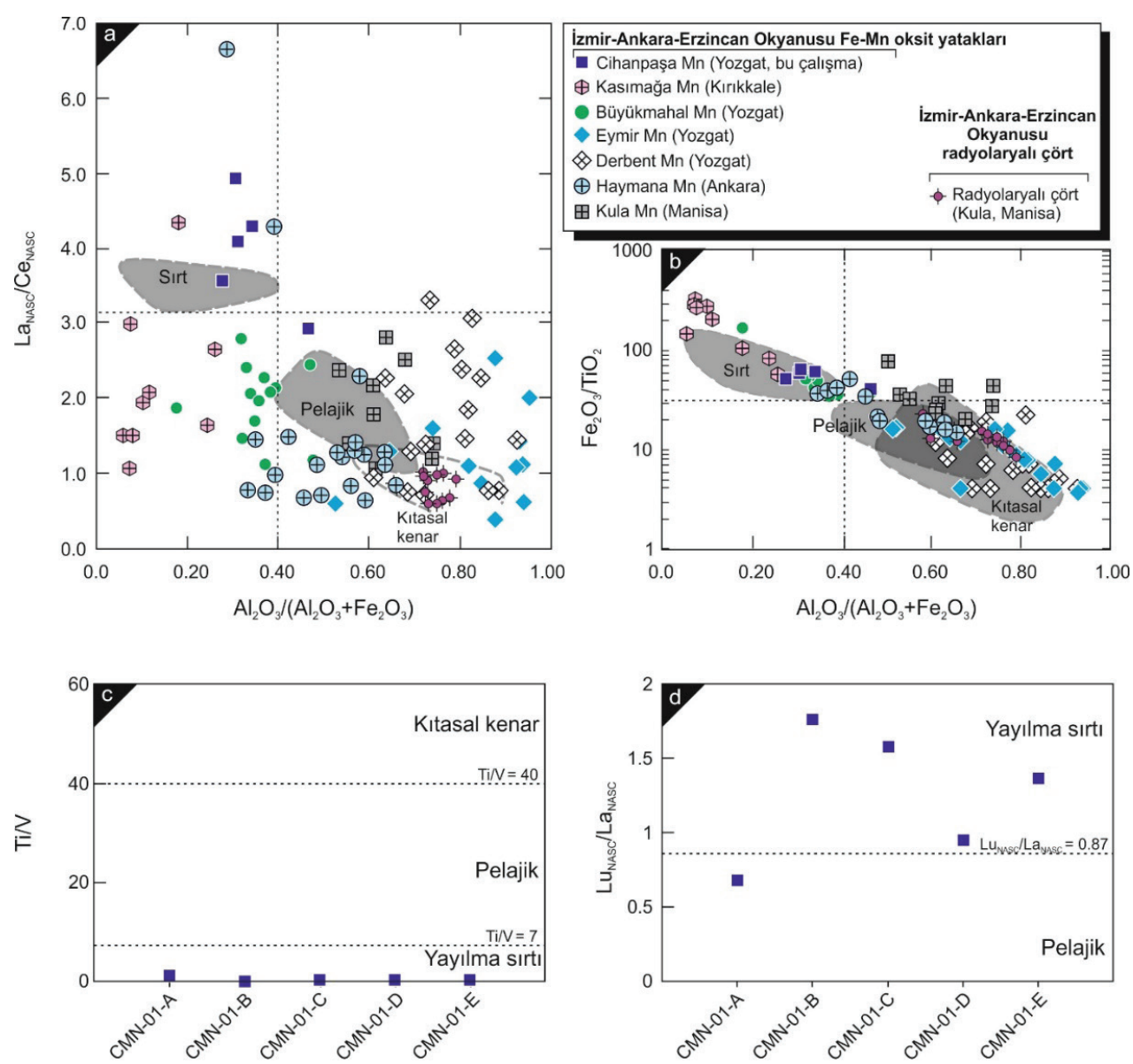

Şekil 8. a) $\mathrm{La}_{\mathrm{NASC}} / \mathrm{Ce}_{\mathrm{NASC}}-\mathrm{Al}_{2} \mathrm{O}_{3} /\left(\mathrm{Al}_{2} \mathrm{O}_{3}+\mathrm{Fe}_{2} \mathrm{O}_{3}\right)$ diyagramı. b) $\mathrm{Fe}_{2} \mathrm{O}_{3} / \mathrm{TiO}_{2}-\mathrm{Al}_{2} \mathrm{O}_{3} /\left(\mathrm{Al}_{2} \mathrm{O}_{3}+\mathrm{Fe}_{2} \mathrm{O}_{3}\right)$. Sirt, pelajik ve kıtasal kenar ortamları Murray (1994)'dan alınmıştır. c) $\mathrm{Ti} / \mathrm{V}$, d) $\mathrm{Lu}_{\mathrm{NASC}} / \mathrm{La}_{\mathrm{NASC}}$ oranlarının ayırım diyagramları (Murray vd., 1991; Murray, 1994).

Figure 8. a) $\mathrm{La}_{\mathrm{NASC}} / \mathrm{Ce}_{\mathrm{NASC}} \mathrm{vS} \mathrm{Al}_{2} \mathrm{O}_{3} /\left(\mathrm{Al}_{2} \mathrm{O}_{3}+\mathrm{Fe}_{2} \mathrm{O}_{3}\right)$ diagram. b) Plots of Fe $\mathrm{O}_{3} / \mathrm{TiO}_{2} \mathrm{vs} \mathrm{Al}_{2} \mathrm{O}_{3} /\left(\mathrm{Al}_{2} \mathrm{O}_{3}+\mathrm{Fe}_{2} \mathrm{O}_{3}\right)$. Fields of the ridge, pelagic, and continental margin, taken from Murray (1994). Discrimination diagrams of ratios $c)$ Ti/V, and (d) $L u_{N A S C} / L a_{N A S C}$ (Murray et al., 1991; Murray, 1994).

Nadir Yer Elementleri (özellikle Ce, Eu) sedimanter sistemlerde günümüz modern ve geçmiş manganez yataklarının depolanma ortamlarını yorumlamada oldukça kuvvetli göstergeler sunmaktadır (Murray vd., 1990; Wright vd., 1987; Piepgras ve Jacobsen, 1992; Owen vd., 1999; Chen vd., 2006). Bu elementlerden, seryum $\mathrm{Ce}^{3+}$ ve $\mathrm{Ce}^{4+}$ şeklinde iki oksidasyon durumuna sahiptir. Oksitleyici denizel ortamlarda, $\mathrm{Ce}^{4+}$ egemendir ve oksik deniz suyunda Fe-Mnoksihidroksitler seryumun fakirleşmesine yol açmaktadır (Elderfield ve Greaves, 1982; De Baar vd., 1988; Gadd vd., 2016). Modern okyanusal ortamlarda, Ce anomalisinin varlığı, su derinliğine bağlıdır. Ce yüzey suyunda yaklaşık 1'dir, ancak deniz suyunun derin kısımlarında hareketli Fe-Mn oksi/hidroksit partikülleri nedeniyle tüketildiği için pozitif Ce anomali gösterirken Ce-bakımından zayıf kalan deniz suyundan çökelimlerde negatif Ce anomalisi sunmaktadır (Gadd vd., 2016). Dolayısıyla, negatif $\mathrm{Ce}$ anomalisi oksijen bakımından zengin deniz suyundan çökelimi ifade etmektedir (Laurilla vd., 2014). 
Murray vd. (1990, 1991, 1992), Ce anomalisi temelinde şeyl ve çört formasyonları için 3 farklı depolanma ortamı tanımlamıştır (hesaplama NASC standart şeyl ortalamalarına göre yapılmıştır, Gromet vd., 1984). Bunlar: 1) yayılma sırtına yakın alanlar $\left(\mathrm{Ce} / \mathrm{Ce}^{*}=\sim 0,29\right)$, 2) okyanus havzası tabanı veya pelajik ortam $(\mathrm{Ce} /$ $\left.\left.\mathrm{Ce}^{*}=\sim 0,55\right), 3\right)$ kitasal kenar ortamları $(\mathrm{Ce} / \mathrm{Ce} *$ $=\sim 0,90-1,30$ ). Cihanpaşa Mn cevherleşmelerinin $\mathrm{Ce} / \mathrm{Ce}$ * anomali değerleri 0,29 ile 0,41 arasında değişmektedir $(\sim 0,34)$. Bu değerler, çalışmanın konusunu oluşturan cevherleşmelerin daha çok yayılma sırtına yakın, yayılma sırtı ile pelajik ortam arasında bir depolanma kısmında çökelim yaptığını göstermektedir. Bu, $\Sigma \mathrm{NYE/}$ Fe oranları ile de desteklenebilmektedir. Doğu Pasifik Sırtına (East Pasific Ridge, EPR) oldukça yakın olan hidrotermal sedimentlerde $\Sigma \mathrm{NYE} /$ Fe oran $16,2 \times 10^{-4}$ civarındadır. Bununla birlikte, EPR'den $802 \mathrm{~km}$ uzaklikta olan hidrotermal

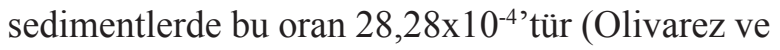
Owen, 1989). Cihanpaşa Mn cevherleşmelerinin $\Sigma \mathrm{NYE} / \mathrm{Fe}$ oran1 $24,4 \times 10^{-4}-43,3 \times 10^{-4}$ arasinda değişmektedir. Ortalama $\Sigma \mathrm{NYE} / \mathrm{Fe}$ oran $130,7 \times 10^{-4}$ ile Büyükmahal (Yozgat) Fe-Mn yatağına ( $\Sigma$ NYE/ $\mathrm{Fe}=30,26 \times 10^{-4}$; Öksüz ve Okuyucu, 2016) oldukça benzer değerler sunmaktadır ve bu değer, Olivarez ve Owen (1989) tarafından verilen çalışma konusu cevherleşmelerin İzmir-AnkaraErzincan okyanusunun yayilma sirt kismına çok uzak olmayan bir lokasyonda depolandığını göstermektedir.

Nadir yer element kompozisyonları, denizaltı ortamda bazaltik karakterli okyanusal kabuğun yüksek sıcaklıklı hidrotermal sıvılar ile alterasyona uğrayıp uğramadığı ya da bu ortamlarda çökelimle Mn ve Fe gibi yatakların oluşumunda düşük ya da yüksek sıcaklık hidrotermal sıvıların etkin olup olmadığ1 ile ilgili güçlü bilgiler vermektedir. Bu bağlamda, Eu anomalisi bazaltik okyanusal kabuğun düşük ya da yüksek sicaklık hidrotermal alterasyonunun aydınlatılmasında kullanılmaktadır. Pozitif ya da negatif Eu anomalisi solüsyon sıcaklığ ile ilişkili hidrotermal aktiviteleri ortaya koymada önemlidir. Yaygın olarak, yüksek sicaklık $\left(>350^{\circ} \mathrm{C}\right)$ hidrotermal sivılar tipik olarak okyanus ortası sirt ve yay gerisi yayılma merkezlerinde gelişmektedir ve oldukça güçlü pozitif Eu anomaliler göstermektedir. Oysa, negatif yada oldukça zayıf $\mathrm{Eu}$ anomalisi tipik olarak düşük sıcaklık $\left(<350^{\circ} \mathrm{C}\right.$; Bau and Dulski, 1999) hidrotermal sistemler ile ilişkilidir. Oksijen bakımından zengin derin deniz suları (>2000 m) ortalama bir negatif Eu anomalisi göstermektedir, ancak yayılma sırtı boyunca gözlenen yüksek sıcaklık hidrotermal sıvılar oldukça güçlü $\mathrm{Eu}$ anomalisi ( 70) sunmaktadirlar (Douville vd, 1999). Kato vd. (2006), yüksek sicaklık koyu buğu (black smoker) sıvılarında tespit edilen $\mathrm{Eu}$ anomalilerinin 7,2 ile 15,1 arasında değiştiğini rapor etmiştir. Negatif ve oldukça zayıf pozitif Eu anomalileri, Cihanpaşa manganez cevherleşmelerinin düşük hidrotermal sıvıların etkileri ile oluştuğunu göstermektedir. Alexander vd. (2008)'ne göre, deniz alt1 sedimentlerdeki bazı nadir yer element içeriklerinin oranları, bu sedimentlerdeki nadir toprak elementlerinin dağılımı üzerine hidrotermal sıvı girişinin katkısını ve deniz suyu ile yüksek sıcaklık hidrotermal sıvıların karışımını tanımlamaktadır. Bu çalışmada, hidrotermal sıvı ve deniz suyunun karışımını gösteren bazı nadir yer element oranları ( $\mathrm{Sm} / \mathrm{Yb}, \mathrm{Eu} / \mathrm{Sm}, \mathrm{Y} / \mathrm{Ho})$ kullanılmıştır. Yüksek sıcaklık hidrotermal sıvılar yüksek $\mathrm{Eu} / \mathrm{Sm}(>2)$ ve $\mathrm{Sm} / \mathrm{Yb}(>4)$ oranına sahiptirler, ancak düşük sıcaklık hidrotermal sıvılar bu değerlerden daha düşük $\mathrm{Sm} / \mathrm{Yb}$ ve $\mathrm{Eu} / \mathrm{Sm}$ oranı göstermektedirler (Alexander vd., 2008). Cihanpaşa Mn cevherleşmelerinde düşük $\mathrm{Eu} / \mathrm{Sm}(\sim 0,22)$ ve $\mathrm{Sm} /$ $\mathrm{Yb}(1,03)$ oranları deniz suyu ile düşük sıcaklık hidrotermal sıvıların değerleri arasındadır. Dolayısıyla, elde edilen değerler yüksek sıcaklık hidrotermal sıvılardan ayrılmakla birlikte düşük sıcaklık hidrotermal sıvılar ile deniz suyunun bir karışımını ifade etmektedir (Lei vd., 2020). 
Denizel sedimantasyon ortamlarında deniz suyunun tuzluluğu çökelimle yakından ilişkilidir ve Sr değerleri tuzluluk ile doğru orantılıdır (Klein vd., 1996, s. 4217). Güncel okyanus tuzluluk değerleri ile Sr ilişkisi bunu kanıtlar niteliktedir. Genel olarak, denizin tuzluluğunun artmasina paralel olarak Sr yoğunlaşması da artmaktadır (Klein vd., 1996). Bu bilgiler 1şığında eski okyanusların tuzluluğu hakkında $\mathrm{Sr}$ değerleri incelenerek göreceli bilgi edinilebilmektedir. Çizelge 2'de ve Şekil 9'da, bazı manganez oksit yataklarının Sr içeriklerinine göre karşılaştırılması verilmiştir. $\mathrm{Bu}$ çalışmada elde edilen düşük $\mathrm{Sr}$ içerikleri ( 401 ppm) bu cevherleşmelerin normal tuzluluğa sahip bir ortamda çökelim yaptığını işaret etmektedir. Xie vd. (2013)'e göre, Guichi (Çin) manganez örneklerinde tespit edilen yüksek Sr içerikleri (1.500 ppm'den daha yüksek), bu cevherleşmelerin yüksek tuzluluğa sahip bir sedimanter ortamda oluştuğunu göstermektedir. Türkiye'den örnek olarak, Kula (Manisa) bölgesindeki, Vezirler melanjına ait radyolaryalı çörtler içerisinde gözlenen manganez yatağında tespit edilen oldukça yüksek Sr (20.178 ppm'e kadar, 4.491 ppm) içerikleri, bu manganezlerin oldukça tuzlu bir depolanma ortamında oluştuğunu işaret etmektedir (Kılıç vd., 2018). Cihanpaşa bölgesinde tespit edilen korunmuş Mn nodülleri, yüksek Sr ( 2.471 ppm) içeriklerine sahiptir (yayımlanmamış veri). Buna ek olarak, Triyas yaşlı Tavşanlı Zonu (KB Türkiye) mavi şistlerin içinde metamorfizmaya uğramış manganez oluşumlarında ilksel verilere göre Kula bölgesindeki manganez oluşumlarına benzer şekilde, yüksek Sr (7.860 ppm'e kadar, -3.727 ppm) içerikleri tespit edilmiştir (yayımlanmamış veri; Şekil 9). Büyükorhan (Bursa) bölgesi metamorfizmaya uğramış manganez yatağı, Neotetis Okyanusu'na ait ilk kabuğun kırılmadan önceki bir zaman dilimde oluşmuş olabileceği tahmin edilmektedir. İAESZ boyunca radyolaryalı çört istifi içerisinde gözlenen mangan yataklarının, Nasirabad ve Esfandaghe (İran) bölgesi mangan yataklarının ve Dounan (Çin) mangan yataklarının Sr içerikleri ise oldukça düşüktür (Şekil 9). Duan vd. (2019), Dounan (Çin) bölgesindeki manganez yatağında elde ettikleri negatif $\mathrm{Ce}$ anomalisi $(0,74-1,23, \sim 0,96) \quad$ değerlerinin bölgedeki cevherleşmelerin kitasal kenar ortamında şekillendiğini ve otojenik komponentlerdeki düşük Sr (96,2 ile 743 ppm) içeriklerinin normal tuzluluğa sahip bir depolanma ortamını işaret ettiğini belirtmişlerdir. Yazarlar, sahada kurak bir iklimde oluşan jips oluşumlarına rastlanmamasını, manganez cevherleşmelerinin sı̆̆-denizel bir ortamda bir kitasal kenar boyunca normal tuzlu ortam koşulları ile 1lık-hafif sıcak iklim koşulları altında oluştuklarını ifade etmişlerdir.

Dünya genelinde Mesozoyik'te eski okyanus suyu tuzlulukları incelendiğinde, Geç Triyas (\%o39,78-44,16) - Erken Jura (\%o39,81-44,32), tuzluluğun en fazla olduğu dönemdir ve Kretase döneminde deniz tuzluluğu kademeli olarak düşmektedir (Şekil 10b; Hay vd., 2006). Devam eden evaporasyon ile birlikte deniz suyunun tuzluluğu da artmaktadır. Akdeniz bölgesinde ve Türkiye'de denizel evaporitik oluşumlar bazı yazarlar tarafından çalışılmış ve yaygın olarak bu oluşumların Üst Triyas'dan Orta Jura'ya kadar değişen yaşlara sahip oldukları rapor edilmiştir (Patacca vd., 1979; Gündoğan vd., 2008; Escavy vd., 2012; Santantonio vd., 2013). Akdeniz bölgesindeki Triyas yaşlı evaporitler Fransa, Almanya, İspanya, Tunus, Suriye ve İsrail'de gözlenmektedir (Gündoğan vd., 2008). Türkiye'de, Honaz (Denizli, Türkiye)' da özellikle yüksek tuzluluğa işaret eden denizel evaporitler, bir tektonik dilim şeklinde Triyas yaşlı koyu renkli dolomitik karbonatlar içerisinde gözlenmektedir (Gündoğan vd., 2008). Dahas1, Kozan (Adana) bölgesi, Seyhan nehri üzerinde sı̆̆ karbonatlar içerisinde 30 m'den daha fazla kalınlığa sahip Triyas yaşlı anhidrit bakımından zengin evaporitler Baraj bent kısmında tespit edilmiştir (Helvacı, 2021, sözlü görüşme). 
Çizelge 2. Mn-oksit yatakların farklı tipleri ve ortalama $\mathrm{Sr}(\mathrm{ppm})$ içerikleri.

Table 2. Average Sr concentrations of different types of Mn-oxide deposits.

\begin{tabular}{|c|c|c|c|}
\hline Bölge & Yatak & Ana kayaç & $\mathrm{Sr}$ (ppm) \\
\hline Esfandaghe (İran) ${ }^{(1)}$ & $\mathrm{Mn}$ & Radyolarit çört, şeyl & 267 \\
\hline Nasirabad (İran) ${ }^{(2)}$ & Mn & Radyolarit çört & 577 \\
\hline Dehoo (İran) $)^{(3)}$ & Mn & Radyolaryalı çört & 2.370 \\
\hline Dounan $(\text { Çin })^{(4)}$ & $\mathrm{Mn}$ & Karbonat, klastik türbidit & 410 \\
\hline Guichi (Çin) ${ }^{(5)}$ & Mn & Kalker, arjilikli, silisli kayaçlar & 1.253 \\
\hline $\begin{array}{l}\text { Haymana (Ankara) } \\
\text { Ankara melanj1 }\end{array}$ & $\mathrm{Mn}$ & Radyolarit, marn & 243 \\
\hline $\begin{array}{l}\text { Eymir (Yozgat) }{ }^{(7)} \\
\text { Artova melanj1 }\end{array}$ & $\mathrm{Mn}$ & Radyolarit & 116 \\
\hline $\begin{array}{c}\text { Derbent (Yozgat) } \\
\text { Artova melanj1 }\end{array}$ & $\mathrm{Mn}$ & Radyolarit & 472 \\
\hline $\begin{array}{l}\text { Büyükmahal (Yozgat) }{ }^{(9)} \\
\text { Artova melanj1 }\end{array}$ & Fe-Mn & Radyolarit & 492 \\
\hline Cihanpaşa (Yozgat) ${ }^{(10)}$ Artova melanj1 & Mn nodül & Radyolaryalı çört, çamurtaşı & 2.471 \\
\hline $\begin{array}{c}\text { Cihanpaşa (Yozgat) })^{(11)} \\
\text { Artova melanj1 }\end{array}$ & Fe-Mn & Radyolaryalı çört & 243 \\
\hline $\begin{array}{l}\text { Cihanpaşa (Yozgat) } \\
\text { Artova melanj1 }\end{array}$ & $\mathrm{Mn}$ & Radyolaryalı çört & 401 \\
\hline $\begin{array}{l}\text { Kasımağa (Kırıkkale) })^{(13)} \\
\text { Kasımağa Formasyonu }\end{array}$ & $\mathrm{Fe}-\mathrm{Mn}$ & Bazalt, radyolarit, marn & 255 \\
\hline $\begin{array}{l}\text { Tafak (Balıkesir) }{ }^{(14)} \\
\text { Dağardı melanjı }\end{array}$ & $\mathrm{Mn}$ & Radyolaryalı çört & 82 \\
\hline $\begin{array}{l}\text { Demirciler (Balıkesir) }{ }^{(15)} \\
\text { Dağardı melanjı }\end{array}$ & $\mathrm{Mn}$ & Radyolaryalı çört & 127 \\
\hline $\begin{array}{l}\text { Kula (Manisa) }{ }^{(16)} \\
\text { Vezirler melanj1 }\end{array}$ & $\mathrm{Mn}$ & Radyolaryalı çört & 4.491 \\
\hline $\begin{array}{l}\text { Büyükorhan (Bursa) }{ }^{(17)} \\
\text { Piribeyler șisti (mavișist) }\end{array}$ & $\mathrm{Mn}$ & Metamorfize radyolaryalı çört & 3.727 \\
\hline
\end{tabular}

(1)Ahmadi vd. (2019), (2)Zarasvandi vd. (2013), ${ }^{(3)}$ Lotfi vd. (2017), ${ }^{(4)}$ Duan vd. (2019), ${ }^{(5)}$ Xie vd. (2013), ${ }^{(6)}$ Karakuş vd. (2010), ${ }^{(7)}$

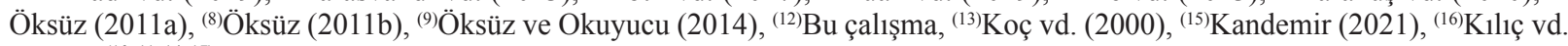
(2018), ${ }^{(10,11,14,17)}$ Yayımlanmamış veri.

Ayrıca, Adıyaman bölgesinde TPAO tarafindan sondajlarda Triyas yaşlı evaporitler tespit edilmiş olup, kalınlığı ile ilgili herhangi bir bilgi literatürde yoktur (Helvac1 (2021), sözlü görüşme). Kurtalan (Siirt) bölgesinde, Germik Fosmasyonu içerisindeki jipslerden alınan izotop analizleri bu jipslerin Triyas yaşlı evaportiler ile ilişkiliolduğunu göstermektedir. İAESZ'den uzak kesimlerde Kula bölgesinde ve Triyas yaşlı Tavşanlı zonu içerisindeki mangan cevherleşmelerinde tespit edilen oldukça yüksek $\mathrm{Sr}$ değerleri ile denizel evaporitlerin Triyas yaşlı olması, herhangi bir yaş verisi olmamasına rağmen Kula bölgesi mangan cevherleşmelerinin de yaklaşı olarak bu dönemde oluşmuş olabileceğini düşündürmektedir. Türkiye'de, İAESZ boyunca farklı melanj birlikleri içerisindeki radyolaryalı çörtlerden alınan radyolarya faunaları sistematik olarak incelenmiş ve yaşlandırılmıştır (Şekil 10 a ve b). 


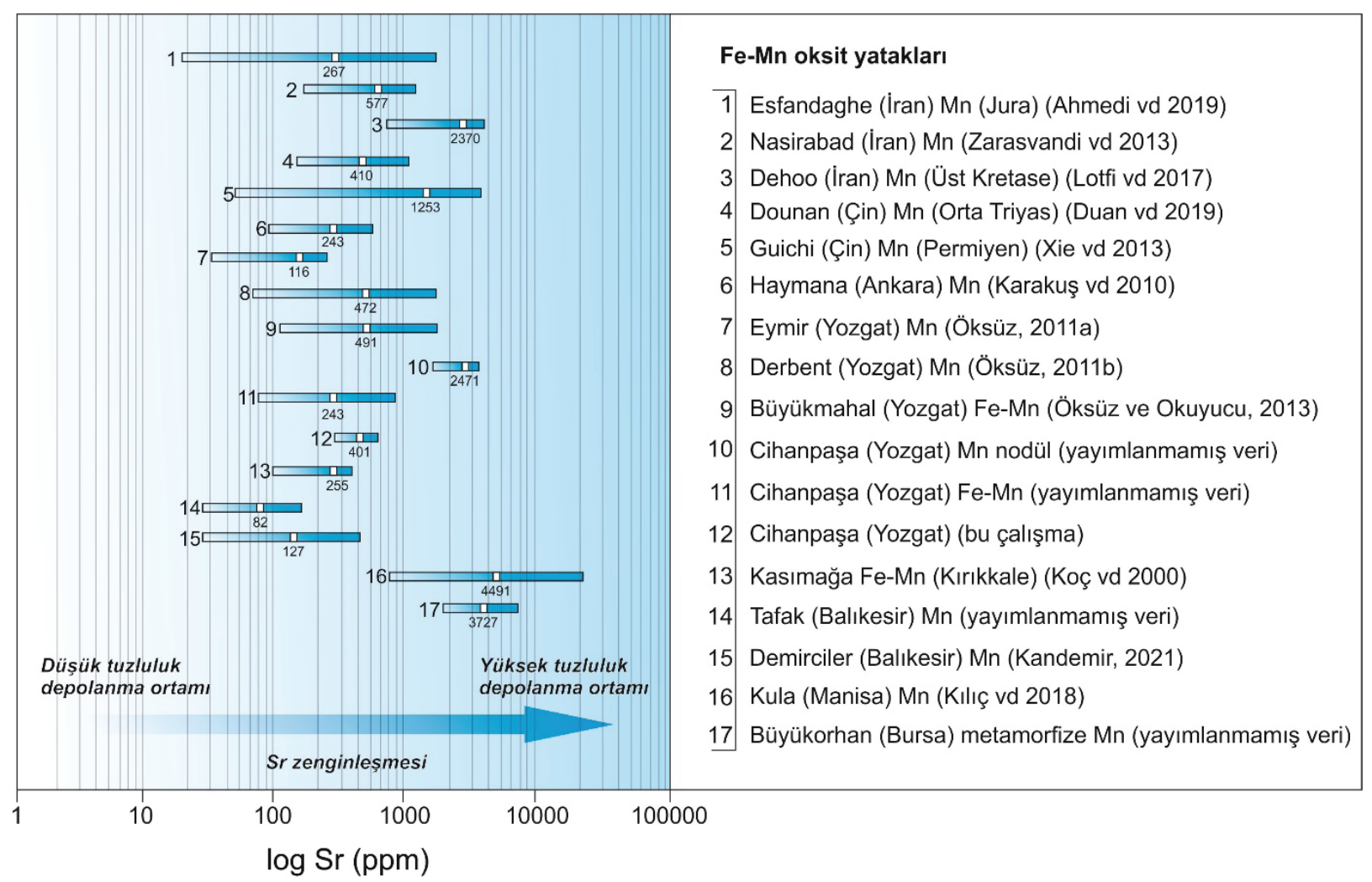

Şekil 9. Türkiye'den ve Dünya'dan manganez cevherleşmelerinin ortalama logaritmik $\mathrm{Sr}$ (ppm) içerikleri. Yüksek Sr içeriği yüksek tuzluluk depolanma ortamını ve düşük Sr içeriği düşük tuzluluk depolanma ortamını göstermektedir.

Figure 9. Average log Sr (ppm) contents of manganese mineralizations from Turkey and worldwide. High $\mathrm{Sr}$ content indicates a high salinity depositional environment, but low Sr content suggests a low salinity depositional environment.

$\mathrm{Bu}$ çalışmalar temelinde tespit edilen radyolarya fosilleri, radyolaryalı çörtlerin İzmir-AnkaraErzincan okyanusunun Orta Triyas'tan Geç Kretase'ye kadar bir zaman aralığında çökelim yaptığını göstermektedir (Şekil 10 a ve b). İAESZ boyunca tespit edilen radyolarya yaşlarının Jura-Kretase döneminde yoğunluk göstermesine rağmen, Triyas döneminden elde edilen yaşlar oldukça azdır ve OrtaGeç Triyas yaşlı radyolarya fosilleri Ankara melanj1, Dağküplü melanjı ve Bornova filiş zonundan rapor edilmiştir (Bortolotti vd., 2018; Göncüoğlu vd., 2010; Tekin ve Göncüoğlu, 2007; Tekin vd., 2006; Şekil 10b). Dolayısıyla, Triyas döneminde, radyolarya faunalarının daha az gözlenmesi, bu zaman diliminde çökelim yapan silisli sedimanter kayaçların ve içerdiği manganez cevherleşmelerinin daha yoğun bir şekilde incelenmesini gerektirmektedir. Özellikle melanj birlikleri içerisinde radyolaryalı çörtler ile birlikte koyu renkli dolomit içerikli neritik (sığ) karbonatların ve eğer içeriyorsa evaporitik oluşumların (jips, anhidrit) keşfedilmesi ile önceki okyanus suyu depolanma koşulları hakkında yeni veriler literatüre kazandırılabilecektir (Helvacı, 2021 sözlü görüşme). Sonuç olarak, burada tartışılan yüksek $\mathrm{Sr}$ değerlerine sahip mangan cevherleşmelerinin bulunduğu lokasyonlarda yapılacak paleontolojik çalışmalarla İzmirAnkara-Erzincan okyanusunun havza oluşumu ve bu okyanusun ortam koşulları hakkında bilgiler aydınlatılabilecek ve bugüne kadar elde edilen bilgilere yenileri eklenmiş olacaktır. 


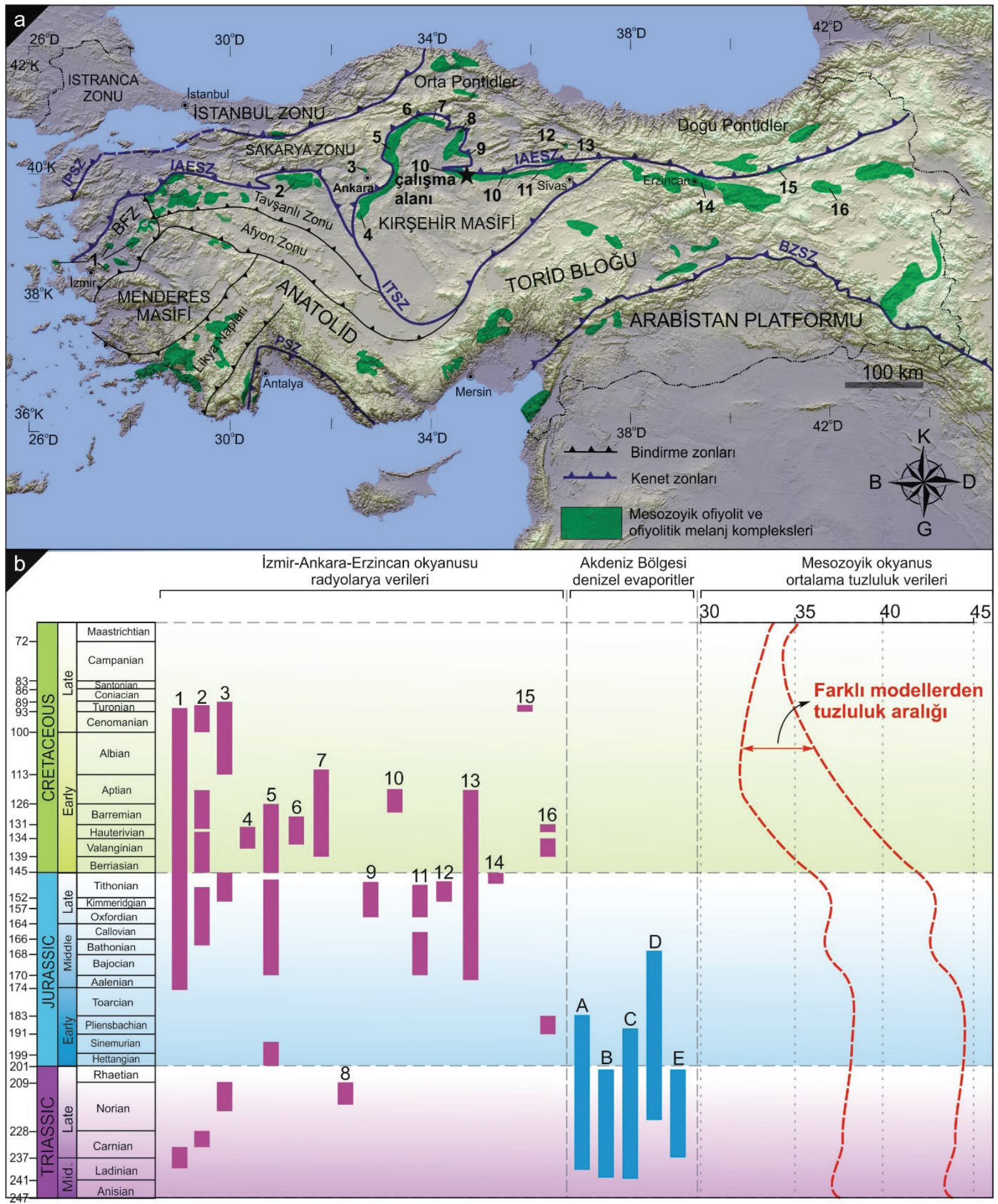

Şekil 10. a) Türkiye'nin kuzey kesiminde ofiyolit-ofiyolitik melanj kompleksleri ve ana kenet zonlarını gösteren basitleştirilmiş kabartma harita (Şengör ve Yılmaz, 1981; Okay ve Tüysüz, 1999; Çelik vd, 2011). b) İzmir-AnkaraErzincan kenet zonu ile ilişkili lokasyonlar ve radyolarya verileri ve Akdeniz bölgesinde evaporit verileri (Gündoğan vd., 2008). Mesozoyik süresince okyanusun ortalama tuzluluğunu gösteren grafik (Hay vd., 2006). Kronostratigrafik 
grafik Cohen (2013)'den alınmıştır. Alan ve lokasyon numaraları: Bornova melanjı: (1) Göncüoğlu vd. (2006a, 2006b); Tekin vd. (2006); Çakmakoğlu ve Bilgin (2006); Tekin ve Göncüoğlu vd. (2007, 2009); Moix ve Goričan (2013); Dağküplü melanjı: (2) Göncüoğlu vd. (2000, 2006b, 2010), ve Tekin vd. (2002); Ankara melanjı: (3) Bragin ve Tekin (1996), Tekin (1999); Ankara melanjı: (4) Üner (2010); Çankırı bölgesi: (5) Çelik (2010); Ankara melanjı: (6-11) Bortolotti vd. (2018); Tokat bölgesi: (12) Bozkurt vd. (1997); Tekelidağ melanjı: (13) Özkan vd. (2020); Erzincan bölgesi: (14) Robertson vd. (2014); Otlukbeli melanjı: (15), Şahvelet melanjı: (16) Robertson vd. (2014). b) Evaporit yatakları: (A-E) (Patacca vd., 1979; Gündoğan vd., 2008; Escavy vd., 2012; Santantonio vd., 2013)

Figure 10. a) Simplified relief map showing main suture zones and ophiolite-ophiolitic melange complex in northern Turkey, from Şengör and Yllmaz (1981), Okay and Tüysüz (1999), and Çelik et al. (2011). b) Locations and radiolarian data related to Izmir-Ankara-Erzincan Suture Zone and evaporate data in Mediterranean region (Gündoğan et al., 2008). Reconstruction of mean salinity of ocean during Mesozoic (Hay et al., 2006). Chronostratigraphic chart is from Cohen (2013). Key to area and location numbers: Bornova mélange: (1) Göncüoğlu et al. (2006a, 2006b); Tekin et al., (2006); Çakmakoğlu and Bilgin (2006); Tekin and Göncüoğlu et al. (2007, 2009); Moix and Goričan (2013); Dağküplü mélange: (2) Göncüoğlu et al. (2000, 2006b, 2010), and Tekin et al. (2002); Ankara mélange: (3) Bragin and Tekin (1996), Tekin (1999); Ankara mélange: (4) Üner (2010); Çankırı region: (5) Çelik (2010); Ankara mélange: (6-11) Bortolotti et al. (2018); Tokat region: (12) Bozkurt et al. (1997); Tekelidağ mélange: (13) Özkan et.al. (2020); Erzincan region: (14) Robertson et al. (2014); Otlukbeli mélange: (15), Şahvelet mélange: (16) Robertson et al. (2014). Evaporitic deposits: (A-E) (from Patacca et al., 1979; Gündoğan et al., 2008; Escavy et al., 2012; Santantonio et al., 2013)

\section{SONUÇLAR}

Türkiye'nin kuzey kesiminde doğu-batı uzanımlı Neotetis Okyanusu'nun kuzey kolunu temsil eden İAESZ'ye ait olan Artova ofiyolitik melanjına ait radyolaryalı çört birimleri birçok lokasyonda (Eymir, Derbent, Büyükmahal, Cihanpaşa) manganez ve ferromanganez yataklarına ev sahipliği yapmaktadır. Bunlardan, Cihanpaşa (Yozgat, İç Anadolu) manganez cevherleşmelerini temsil eden 5 adet örnek üzerinde gerçekleştirilen jeokimyasal analizler temelinde, yüksek $\mathrm{Mn} / \mathrm{Fe}$ $(60,2)$, düşük $\Sigma$ NYE $(15,75$ ppm), $\mathrm{Cu}+\mathrm{Ni}+\mathrm{Co}$ (730 ppm) içerikleri ile bölgedeki cevherleşmeler, İzmir-Ankara-Erzincan okyanusunun denizalt bir hidrotermal sistemin etkisi ile oluştuğunu göstermektedir. Diğer taraftan, düşük $\mathrm{Sr}$ değerleri (401 ppm), negatif $\mathrm{Ce}_{\text {PAAS }}$ anomalisi $(0,33)$, düşük $\mathrm{Ce}_{\text {anom }}$ değerleri $(<-0,54)$, redoks işaretleyiciler $[\mathrm{V} /(\mathrm{V}+\mathrm{Ni})=0,43, \mathrm{Ni} / \mathrm{Co}=0,51, \mathrm{~V} / \mathrm{Mo}=6,15)]$, çalışılan manganez cevherleşmelerinin oksijenli ve normal tuzluluklu okyanusal sedimanter bir ortamda oluştuğunu ortaya koymaktadır. Buna ek olarak, hafif negatif $\mathrm{Eu}$ anomalisi $(0,84)$, yüksek $\mathrm{La}_{\mathrm{NASC}} / \mathrm{Ce}_{\mathrm{NASC}}(3,96)$, düşük $\mathrm{Al} /(\mathrm{Al}+\mathrm{Fe})$ $(0,34)$ ve $\Sigma \mathrm{NYE} / \mathrm{Fe}\left(30,7 \times 10^{-4}\right)$ oranları, çalışılan manganez oksit cevherleşmelerinin okyanusun kısmen yayılma sırtına yakın düşük sıcaklıklı hidrotermal sistemin etkisi ile şekillenmiş olduğunu göstermektedir.

Günümüzdeki modern okyanuslara benzer olarak, geçmiş jeolojik zamanlarda hüküm süren okyanus tabanında oluşmuş metalik cevherleşmeler, okyanus havzasının kapanması ile birlikte eski kıta kabuğu üzerine eklenir prizmalar şeklinde itilmiş olarak gözlenmektedir. $\mathrm{Bu}$ yataklar, muhtemel ilksel hali bozulmuş ve parçalanmış şekilde ofiyolitik melanj birimleri içerisinde mostra verebilmektedir. Bölgede birçok cevherleşmeye ev sahipliği yapan Artova ofiyolitik melanj1, İAESZ boyunca gözlenen en iyi lokasyonlardan biridir. Bölgede, radyolaryalı çört ve çamurtaşları içerisinde korunmuş mangan nodülleri tespit edilmiş olup, üzerinde çalışmalar devam etmektedir. Buna ek olarak, Cihanpaşa ve civarında altere mafik volkanik kayaç birlikleri içerisinde sülfid cevherleşmeleri de gözlenmektedir $(\mathrm{Pb}=8.995 \mathrm{ppm}, \mathrm{Cu}=1.403 \mathrm{ppm}$, $\mathrm{Zn}=2.124 \mathrm{ppm}, \mathrm{Bi}=227 \mathrm{ppm}$; yayımlanmamış veri). Sonuç olarak, bölgede melanja ait birimlerin 
dikkatli bir şekilde incelenerek baz metal içerikleri bakımından zengin lokasyonlarda detay çalışmalar yapılması ile yeni cevher keşifleri ortaya çıkabilecektir.

\section{EXTENDED SUMMARY}

Many of the manganese oxide deposits occurring in Turkey are associated with the evolution of the Paleotethys and Neotethys Oceans. Anatolia was formed from the combination of many micro-continental fragments with the closure of branches of the Neotethys Ocean. The IzmirAnkara-Erzincan Suture Zone (IAESZ) comprises many ophiolitic melange units. This zone is one of the important suture zones in the eastern Mediterranean region and represents the northern branch of the Neo-Tethyan Ocean. The majority of manganese oxide deposits outcrop in radiolarian chert lithologies observed in ophiolitic melange units along or near the IAESZ in the form of large and small blocks. Of these mélange units, the Artova ophiolitic mélange outcrop is between the Sakarya Continent to the north and the Kirşehir Massif to the south (Fig. 1). This mélange comprises blocks of serpentinite, radiolarian chert, pelagic limestone, mudstone and pillow lavas within the serpentinitic mixture. In the region, radiolarian cherts hosting many Mn-oxide deposits are found on the pillow lavas of basaltic character (Figures 2, 3). Paleontological ages from radiolarian cherts and micritic limestones in different locations throughout the IAESZ yield Middle Triassic and Late Cretaceous ages.

Geochemically, analyzed samples have concentrations of MnO 14-51 wt \% ( 34.7wt \%), $\mathrm{SiO}_{2} 32-81$ wt \% ( 55.9\%), $\mathrm{Fe}_{2} \mathrm{O}_{3} 0.5-1.1 w t \%$ ( $\sim 0.68 w t \%), \mathrm{Al}_{2} \mathrm{O}_{3} 0.19-1.02 w t \%(\sim 0.4 w t \%)$, and $\mathrm{CaO} w \mathrm{w} \%$. They have values ranging between $0.21-0.86(\sim 0.47 w t \%)$ and a total alkali of $\left(\mathrm{Na}_{2} \mathrm{O}+\mathrm{K}_{2} \mathrm{O}\right)$ 0.06-0.11wt\% ( 0.09wt \%). Most trace elements of all samples include Ni (158 to 268 ppm), Co (339 to 525 ppm), Ba (3031 to 4543 ppm), Sr (263 to $562 \mathrm{ppm}$ ), and Zn (50 to $151 \mathrm{ppm}$ ). The average Co/Ni ratio of the studied manganese mineralizations is $2.09 \mathrm{ppm}$, and the Co/Zn ratio is 5.26 on average; these values are higher than the values given in the literature for hydrothermal manganese deposits due to Co enrichment. The fact that the studied manganese mineralizations have low $\mathrm{Ni}+\mathrm{Cu}$ values (182-431 ppm, 292 ppm) and high $\mathrm{Mn} / \mathrm{Fe}$ (26-111 ppm, $\sim 60.18 \mathrm{ppm})$ ratios is consistent with the values of hydrothermal deposits. The Co ( 438 ppm), low Ce ( 3.2 ppm) and $\mathrm{Tl}(\sim 6.3 \mathrm{ppm})$ content of the Cihanpaşa manganese mineralizations indicate that these mineralizations are not related to hydrogenetic formations; on the contrary, they are similar to hydrothermal manganese mineralizations.

The Y/Ho ratio of the Cihanpaşa manganese mineralizations is $\sim 23$, indicating that they are not affected by clastic input or only partially affected. The fact that there is a weakly positive relationship (0.48) between the $\mathrm{Zr}$ and Y/Ho of the Cihanpaşa Mn mineralizations indicates that the detrital phases are limited. The PAASnormalized diagram shows that Cihanpaşa Mn mineralizations have a negative Ce anomaly, and a negative and positive Eu anomaly (Figure 4). These mineralizations have characteristic features with light rare earth elements and medium rare earth element depletion, compared to heavy rare earth elements $\left(G d_{P A A S} / Y b_{P A A S}<1\right.$ ( 0.76); La $a_{P A A S}$ $\left.Y b_{P A A S}<1(\sim 0.73)\right)$, and they have negative Ce and positive $G d$ anomalies ranging from 1.12 to 1.36, similar to low-temperature hydrothermal deposits. As shown in Figure 4, the EPR and $M A R$ high temperature hydrothermal fluids present a very strong Eu anomaly and a positive $Y$ anomaly. Modern oxygen-rich seawater shows a significant negative Ce anomaly, and positive La, Y, and Gd (Figure 4), whereas semioxic and anoxic waters lack the negative Ce anomaly. The studied Mn mineralizations are similar to modern seawater and have rare earth element patterns of hydrothermal deposits with a positive La and 
negative Ce anomaly; thus they fall into the true negative Ce anomaly domain (Figure 5).

In order to reveal the origin of the mineralizations, discrimination diagrams were used, and these show that the Cihanpaşa Mn mineralizations are of hydrothermal origin (Figure 6 a-f). The Fe/Mn ratio can be used to reveal the redox properties of manganese deposits and/or the ferromanganese crust in the Cihanpaşa Mn mineralizations. The low $\mathrm{Fe} / \mathrm{Mn}$ ratios varying between 0.01 and 0.07 ( 0.02) indicate that these mineralizations were formed in an oxidized sedimentary environment. $\mathrm{Ce}_{\text {anom }}$. values of the Cihanpaşa Mn mineralizations range between -0.43 and -0.67 , with an average of -0.54 , indicating that they were formed in an oxidative environment with rapid precipitation (Figure 7a). In addition, the $\mathrm{V} /(\mathrm{V}+\mathrm{Ni})(0.40$ to 0.48$)$ and $\mathrm{Ni} /$ Co (0.36 to 0.63) ratios of the Cihanpassa Mn mineralizations represent an oxic environment (Figure 7b).

In marine manganese deposits, the depositional environment is examined on the basis of 3 different areas: 1) the spreading ridge, 2) pelagic (open ocean) environment, 3) continental margin environment. The $\mathrm{Al}_{2} \mathrm{O}_{3} / \mathrm{Al}_{2} \mathrm{O}_{3}$ $+\mathrm{Fe}_{2} \mathrm{O}_{3}$ ) ratio of the studied $\mathrm{Mn}$ deposit, ranging from 0.28 to 0.47 ( 0.34), shows a depositional site between the pelagic environment and the spreading ridge. In addition, the $\left(\mathrm{La}_{S N} / \mathrm{Ce}_{S N}\right)$ $\mathrm{Al}_{2} \mathrm{O}_{3} /\left(\mathrm{Al}_{2} \mathrm{O}_{3}+\mathrm{Fe}_{2} \mathrm{O}_{3}\right)$ and $\mathrm{Fe}_{2} \mathrm{O}_{3}-\mathrm{Al}_{2} \mathrm{O}_{3} /\left(\mathrm{Al}_{2} \mathrm{O}_{3}\right.$ $+\mathrm{Fe}_{2} \mathrm{O}_{3}$ ) diagrams indicate that the Cihanpaşa Mn mineralizations were deposited close to the spreading ridge (Figure $8 a \& b$ ). Ti/V and $V / Y$ ratios are very useful indicators used to interpret depositional environments. The Ti/V ratio of the Cihanpaşa Mn mineralizations varies between 0.25 and 1.18 ( 0.54) (Figure 8c). The $L u_{S N} / L a_{S N}$ ratio of the studied mineralizations corresponds to environments close to the spreading ridge, with 0.68 to 1.75 ( 1.26) (Figure 8d). Additionally, the $\mathrm{Ce} / \mathrm{C} e^{*}$ anomaly is an indicator revealing the depositional site of the mineralizations. The
$\mathrm{Ce} / \mathrm{Ce}$ * anomaly values of the Cihanpaşa $\mathrm{Mn}$ mineralizations, varying between 0.29 and 0.41 $(\sim 0.34)$, show that the mineralizations were mostly deposited in a depositional zone close to the spreading ridge. This phenomenon can also be demonstrated with the $\Sigma$ NYE/Fe ratio. The $\Sigma$ NYE/ $\mathrm{Fe}$ ratio of the Cihanpaşa $\mathrm{Mn}$ mineralizations, varying between $24.4 \times 10^{-4}$ and $43.3 \times 10^{-4}$, suggests that they were deposited at a location not far from the spreading ridge of the Izmir-Ankara-Erzincan Ocean.

The Eu/Eu* anomaly is used to explain the low or high temperature hydrothermal alteration of the basaltic oceanic crust. A positive or negative Eu anomaly is important in revealing hydrothermal activities related to the solution temperature. High temperature $\left(>350^{\circ} \mathrm{C}\right)$ hydrothermal fluids typically develop in mid-ocean ridges and back-arc spreading centers and show very strong positive Eu anomalies. However, a negative or slightly positive Eu anomaly is typically associated with low temperature $\left(<350{ }^{\circ} \mathrm{C}\right.$; Bau and Dulski, 1999) hydrothermal systems. Negative $(0.27,0.90)$ and weakly positive Eu anomalies $(1.20,1.33)$ indicate that the Cihanpaşa manganese mineralizations were formed by the effect of low hydrothermal fluids. In addition, high temperature hydrothermal fluids have high Eu/Sm and $\mathrm{Sm} / \mathrm{Yb}$ ratios, whereas low temperature hydrothermal fluids show high $\mathrm{Sm} / \mathrm{Yb}$ and low Eu/Sm ratios. The Eu/Sm (0.22) and $\mathrm{Sm} / \mathrm{Yb}$ (1.03) ratios of the Cihanpassa $\mathrm{Mn}$ mineralizations are between the values of seawater and low temperature hydrothermal fluids. Therefore, these values denote a mixture of low temperature hydrothermal fluids and seawater.

The $\mathrm{Sr}$ content increases with an increase of seawater salinity, and/or $\mathrm{Sr}$ concentrations in seawater decrease with decreasing salinitiy. Information about the salinity of ancient oceans can be obtained by examining the $\mathrm{Sr}$ values (see Figure 9). The low Sr content ( 401 ppm) obtained in the present study indicates that the Cihanpaşa manganese mineralizations were deposited in 
a normal-salinity sedimentary environment. In western Turkey, high Sr (up to 20178 ppm, 4491 ppm) content detected from the manganese deposits and observed within the radiolarian cherts of the Vezirler mélange in the Kula (Manisa) region indicates that these manganese occurrences were formed in a saline depositional environment. When the ancient ocean water salinities are examined in the Mesozoic period around the world, salinity in the Late Triassic (\%o39.78-44.16)-Early Jurassic (\%o39.81-44.32) period was the highest, and the seawater salinity gradually decreased during the Cretaceous period (Figure 10b). Marine evaporitic occurrences in the Mediterranean region and Turkey yield ages ranging from Upper Triassic to Middle Jurassic. Consequently, information about the basin formation of the Izmir-Ankara-Erzincan Ocean and the environmental conditions of this ocean will be clarified with paleontological studies to be carried out in the regions where manganese mineralizations having high $\mathrm{Sr}$ values are located.

This study is concerned with manganese mineralizations that were previously mined in the southern part of the Cihanpaşa (Yozgat) area. Host rocks (radiolarian cherts) have high $\mathrm{Fe}$ and Mn compositions in the region, and were also deposited close to the spreading ridge of the Izmir-Ankara-Erzincan Ocean. It has been revealed, therefore, that the possibility of metallic sulfide mineralizations in different rock lithologies of the Artova ophiolitic mélange increases with the occurrence of these formations near the ridge and the growing need for mineral exploration in the region. In conclusion, this study was carried out to determine the geochemistry of manganese mineralizations hosted by radiolarian cherts in the region and to research their genesis.

\section{KATKI BELIRTME}

Yazar, çalışmada bilimsel katkı ve destekleri için Dr. Cahit HELVACI'ya, Türkiye Jeoloji Bülteni Baş Editörü Dr. Erdinç YİĞİTBAŞ’a,
Editörler Dr. İsmail Onur TUNÇ’a, Dr. Mustafa AVCIOĞLU'na ve makaledeki değerli bilimsel katkı ve eleştirilerinden dolayı hakemlere teşekkür etmektedir.

\section{ORCID}

M. Selman Aydoğan (D https://orcid.org/0000-0003-2478-8632

\section{KAYNAKLAR / REFERENCES}

Ahmadi, J., Mirnejad, H. \& Modabberi, S. (2019). Geochemical Evidence for the Depositional Environment of the Esfandaghe Manganese Deposit, Kerman Province, Iran. Geochemical International, 57, 266-281.

Akçay, A. E. \& Beyazpirinç, M. (2017). The Geological Evolution of Sorgun (Yozgat)-Yildizeli (Sivas) Foreland Basin, Petrographic, Geochemical Aspects and Geochronology of Volcanism Affecting the Basin. Bulletin of the Mineral Research and Exploration, 155, 1-31.

Akçay, A. E., Dönmez, M., Kara, H., Yergök, A.F. \& Esentürk, K. (2007). 1/100.000 ölçekli Türkiye Jeoloji Haritaları, Yozgat-I33 Paftas1 [1-16]. MTA Genel Müdürlügü̈, Jeoloji Etüdleri Dairesi, Ankara, 80 .

Aldanmaz, E., Yalınız, M. K., Güçtekin, A. \& Göncüoğlu, M. C. (2008). Geochemical characteristics of mafic lavas from the Neotethyan ophiolites in western Turkey: implications for heterogeneous source contribution during variable stages of ocean crust generation. Geological Magazine, 145(1):37-54.

Alexander, B.W., Bau, M., Andersson, P. \& Dulski, P. (2008). Continentallyderived solutes in shallow Archean sea water: rare earth element and $\mathrm{Nd}$ isotope evidence in iron formation from the $2.9 \mathrm{Ga}$ Pongola Supergroup, South Africa. Geochimica et Cosmochimica Acta, 72(2):378-394.

Alibo, D. S. \& Nozaki, Y. (1999). Rare earth elements in seawater: Particle association, shalenormalization, and Ce oxidation. Geochimica et Cosmochimica Acta, 63, 363-372.

Alvi, S.H. \& Shaif, M. (2020). Geochemical signatures of manganese ores around Barbil, Noamundi- 
Koira basin, Singhbhum Craton, Eastern India. Geology, Ecology, and Landscapes. https://doi:10 $.1080 / 24749508.2020 .1720489$.

Bau, M. \& Dulski, P. (1999). Comparing yttrium and rare earths in hydrothermal fluids from the MidAtlantic Ridge: implications for $\mathrm{Y}$ and REE behaviour during near vent mixing and for the $\mathrm{Y} / \mathrm{Ho}$ ratio of Proterozoic seawater. Chemical Geology, 155 (1/2), 77-90.

Bau, M., Koschinsky, A., Dulski, P. \& Hein, J.R. (1996). Comparison of partitioning behaviours of yttrium, rare earth elements, and titanium between hydrogenetic marine ferromanganese crusts and seawater. Geochimica et Cosmochimica Acta, 60, 1709-1725

Bau, M., Möller, P. \& Dulski, P. (1997). Yttrium and lanthanides in eastern Mediterranean seawater and their fractionation during redox-cycling. Marine Chemistry, 56, 123-131.

Bau, M., Schmidt, K., Koschinsky, A., Hein, J., Kuhn, T. \& Usui, A. (2014). Discriminating between different genetic types of marine ferro-manganese crusts and nodules based on rare earth elements and yttrium. Chemical Geology, 381:1-9.

Bolhar, R., Kaber, B. S., Moorbath, S., Fedo, C. M. \& Whitehouse, M. J. (2004). Characterisation of early Archaean chemical sediments by trace element signatures. Earth and Planetary Science Letters, 222, 43-60.

Bolton, B. R., Both, R., Exon, N. F., Hamilton, T. F., Ostwald, J. \& Smith, J. D. (1988). Geochemistry and mineralogy of seafloor hydrothermal and hydrogenetic Mn oxide deposits from the Manus Basin and Bismarck Archipelago region of the southwest Pacific Ocean. Marine Geology, 85, 6587.

Bonatti, E. (1975). Metallogenesis at oceanic spreading centers. Annu Rev Earth Planetary Science, 3, 401-431.

Bonatti, E., Kraemer, T. \& Rydell, H. (1972). Classification and genesis of submarine ironmanganese deposits. In D.R. Horn (Ed.), Ferromanganese Deposits of the Ocean Floor, (pp. 473-489). Harriman, Petersfield, UK

Bortolotti, V., Chiari, M., Göncüoğlu, M. C., Marcucci, M., Principi, G., Saccani, E., Tekin, U.K. \&
Tassinari, R. (2018). The Jurassic-Early Cretaceous basalt-chert association in the ophiolites of the Ankara Mélange, east of Ankara, Turkey: age and geochemistry. Geological Magazine, 155(2), 451478.

Bortolotti, V., Chiari, M., Göncüoğlu, M. C., Marcucci, M., Principi, G., Tekin, U. K., Saccani, E. \& Tassinari, R. (2013) Age and geochemistry of basaltchert associations in the ophiolites of the Izmir-Ankara mélange east of Ankara, Turkey: preliminary data. Ofioliti 38(2), 157-173.

Bozkurt, E., Holdsworth, B. K. \& Koçyiğit, A. (1997). Implications of Jurassic chert identified in the Tokat Complex, northern Turkey. Geological Magazine, 134(1), 91-97.

Bragin, N. Y. \& Tekin, U. K. (1996). Age of radiolarianchert blocks from the Senonian Ophiolitic Melange (Ankara, Turkey). Island Arc, 5, 114-122.

Chen, D., Qing, H., Yan, X. \& Li, H. (2006). Hydrothermal venting and basin evolution (Devonian, South China): constraints from rare earth element geochemistry of chert. Sedimentary Geology, 183, 203-216.

Cohen, K. M., Finney, S. C., Gibbard, P. L. \& Fan, J.-X. (2013; updated) The ICS International Chronostratigraphic Chart. Episodes, 36, 199-204.

Condie, K.C. (1993). Chemical composition and evolution of the Upper Continental Crust: contrasing results from surface samples and shales. Chemical Geology, 104, 1-37.

Crear, D.A., Namson, J., So Chyi, M., Williams, L. \& Feigenson, M.D. (1982). Manganiferous cherts of the Franciscan assemblage: 1. General geology, ancient and modern analogues, and implications for hydrothermal convection at oceanic spreading centres. Economic Geology, 77(3), 519-540.

Çakmakoğlu, A., Bilgin, Z.R. (2006). Pre-Neogene stratigraphy of the Karaburun peninsula (Wof İzmir Turkey). Bulletin of the Mineral Research and Exploration, 132, 33-61.

Çelik, Ö. F., Marzoli, A., Marschik, R., Chiaradia, M., Neubauer, F. \& Öz, İ. (2011). Early-Middle Jurassic intra-oceanic subduction in the İzmirAnkara-Erzincan Ocean, Northern Turkey. Tectonophysics, 509, 120-134. 
Çelik, S. (2010). Taxonomy and biostratigraphy of Jurassic-Early cretaceous radiolarian fauna of the pelagic deposits in Izmir-Ankara-Erzincan suture complex, NE and SW Cankiri, northern Turkey. [Unpublished MSc. Thesis]. Hacettepe University.

De Baar, H.J., German, C.R., Elderfield, H. \& van Gaans, P. (1988). Rare earth element distributions in anoxic waters of the Cariaco Trench. Geochemica et Cosmochimica Acta, 52, 1203-1219.

Douville, E., Bienvenu, P., Charlou, J.L., Donval, J.P., Fouquet, Y., Appriou, P. \& Gamo, T. (1999). Yttrium and rare earth elements in fluids from various deep-sea hydrothermal systems. Geochemica et Cosmochimica Acta, 63, 527-643.

Duan, J., Fu, Y., Zhang, Z., Ma, X. \& Xiao, J. (2019). The metallogenic environment of the Dounan manganese deposit, Southeast Yunnan, China: evidence from geochemistry and Mössbauer spectroscopic. Acta Geochimica, 38(1), 78-94.

Dubinin, A. V., Kunetsov, A. B., Rimskaya-Korsakova, M. N. \& Safin, T.Kh. (2018). Nd and Sr Isotope Composition in the Tooth Enamel from $\mathrm{Fe}-\mathrm{Mn}$ Nodules of the Cape Basin (Atlantic Ocean): Age and Sources. Geochemistry International, 56(12), 1209-1219.

Dubinin, A.V., Uspenskaya, T.Yu., Gavrilenko, G. M. \& Rashidov, V. A. (2008). Geochemistry and Genesis of $\mathrm{Fe}-\mathrm{Mn}$ Mineralization in Island Arcs in the West Pacific Ocean. Geochemistry International, 46(12), 1206-1227.

Dymond, J., Lyle, M., Finney, B., Piper, D. Z., Murphy, K., Conard, R. \& Pisias, N. (1984). Ferromanganese nodules from MANOP sites $\mathrm{H}$, $\mathrm{S}$ and R-control of mineralogical and chemical composition by multiple accretionary processes. Geochimica et Cosmochimica Acta 48(5), 931949.

Elderfield, H. \& Greaves, M. J. (1982). The rare earth elements in seawater. Nature, 296, 214-218.

Engstrom, D. R. \& Wright, H. E. (1984). Chemical stratigraphy of lake sediments as a record of environmental change. In: E.Y., Haworth, J.W.G. Lund (Eds.), Lake Sediments and Environmental History (pp. 11-67). Leicester University Press, Leicester.
Escavy, J. I., Herrero, M. J. \& Arribas, M. E. (2012). Gypsum resources of Spain: Temporal and spatial distribution. Ore Geology Reviews, 49, 72-84.

Fitzgerald, C. E. \& Gillis, K. M. (2006). Hydrothermal manganese oxide deposits from Baby Bare seamount in the Northeast Pacific Ocean. Marine Geology, 225,145-156.

Gadd, M. G., Layton-Matthews, D. \& Peter, J. M. (2016). Non-hydrothermal origin of apatite in SEDEX mineralization and host rocks of the Howard's pass district, Yukon, Canada. American Mineralogist, 101(5),1061-1071.

Galarraga, F., Reategui, K., Martinez, A., Martinez, M., Liamas, J. F. \& Marquez, G. (2008). V/ $\mathrm{Ni}$ ratio as a parameter in palaeoenvironmental characterisation of nonmaturemedium-crude oils from several Latin American basins. Journal of Petroleum Science and Engineering, 61, 9-14.

Gallego-Torres, D., Martinez-Ruiz, F., De Lange, G. J., Jimenez-Espejo, F. J. \& Ortega-Huertas, M. (2010). Traceelemental derived paleoceanographic and paleoclimatic conditions for Pleistocene Eastern Mediterranean sapropels. Palaeogeography, Palaeoclimatology, Palaeoecology, 293, 76-89.

Ganno, S., Njiosseu, T.E.L., Kouankap, N.G.D., Djoukouo, S.A., Moudioh, C., Ngnotue, T. \& Nzenti, J.P. (2017). A mixed seawater and hydrothermal origin of superior-type banded iron formation (BIF)-hosted Kouambo iron deposit, Palaeoproterozoic Nyong series, Southwestern Cameroon: Constraints from petrography and geochemistry. Ore Geology Reviews, 80, 860-875.

Gao, J., Yang, R., Xu, H., Zhang, X., Feng, K. \& Zheng, L. (2018). Genesis of Permian sedimentary manganese deposits in Zunyi, Guizhou Province, SW China: Constraints from geology and elemental geochemistry. Journal of Geochemical Exploration, 192, 142-154.

German, C. R. \& Elderfield, H. (1990). Application of the $\mathrm{Ce}$ anomaly as a paleoredox indicator: the ground rules. Paleoceanography and Paleoclimatology, 5(5), 823-833.

Glasby, G.P. (2006). Manganese: predominant role of nodules and crusts. In: H.D. Schulz, M. Zabel (Eds.) Marine geochemistry (pp. 371-428). Springer, Heidelberg. 
Glasby, G.P., Gwozdz, R., Kunzendorf, H., Friedrich, G. \& Thijssen, T. (1987). The distribution of rare earth and minor elements in manganese nodules and sediments from the equatorial and SW. Pacific. Lithos, 20(2), 97-1 13.

Glasby, G. P., Li, J. \& Sun, Z. (2015). Deep-Sea Nodules and Co-rich Mn Crusts. Marine Georesources \& Geotechnology, 33, 72-78.

Göncüoğlu, M.C., Turhan, N., Şentürk, K., Özcan, A. \& Uysal, S. (2000). A geotraverse across NW Turkey: tectonic units of the Central Sakarya region and their tectonic evolution. In: Bozkurt E, Winchester J, Piper JA (eds) Tectonics and magmatism in Turkey and the surrounding area. Geological Society, London, Special Publications, 173, 139-161.

Göncüoğlu, M. C., Sayıt, K. \& Tekin, U.K. (2010). Oceanization of the northern Neotethys: geochemical evidence from ophiolitic melange basalts within the Izmir-Ankara suture belt, NW Turkey. Lithos, 116, 175-187.

Göncüoğlu, M. C., Yalınız, M. K. \& Tekin, U. K. (2006a). Geochemistry, tectono-magmatic discrimination and radiolarian ages of basic extrusives within the Izmir-Ankara-Suture Belt (NW Turkey): Time constraints for the Neotethyan evolution. Ofioliti, 31, 25-38.

Göncüoğlu, M. C., Yalınız, M. K. \& Tekin, U. K. (2006b). Geochemical features and radiolarian ages of volcanic rocks from the Izmir-Ankara Suture Belt, western Turkey. Mesozoic ophiolite belts of the northern part of the Balkan Peninsula, International Symposium, Belgrade-Banja Luka, May 31-June 6 (pp. 41-44).

Gromet, L.P., Dymek, R.F., Haskin, L.A. \& Korotev, R.L. (1984). The "North American Shale Composite": its compilation, major and trace element characteristics. Geochemica et Cosmochimica Acta, 48(12), 2469-2482.

Gültekin, A.H. \& Balc1, N. (2018). Geochemical Characteristics of Sedimentary Manganese Deposit of Binkılıç, Trache Basin, Turkey. Journal of Geology and Geophysics, 7(3), 1-13.

Gündoğan, İ., Helvacı, C. \& Sözbilir, H. (2008). Gypsiferous carbonates at Honaz Dağı (Denizli): First documentation of Triassic gypsum in western Turkey and its tectonic significance. Journal of Asian Earth Sciences, 32, 49-65.
Halbach, P., Scherhag, C., Hebisch, U. \& Marchig, V. (1981). Geochemical and mineralogical control of different genetic types of deep-sea nodules from the Pacific Ocean. Mineralium Deposita, 16(1), 59-84.

Hatch, J. R. \& Leventhal, J. S. (1992). Relationship between inferred redox potential of the depositional environment and geochemistry of the upper Pennsylvanian (Missourian) stark shale member of the Dennis lime stone, Wabaunsee County, Kansas, U.S.A. Chemical Geology, 99(13), 65-82.

Hay, W. H., Migdisov, A., Balukhovsky, A. N., Wold, C. N., Flögel, S. \& Söding, E. (2006). Evaporites and the salinity of the ocean during the Phanerozoic: Implications for climate, ocean circulation and life. Palaeogeography, Palaeoclimatology, Palaeoecology, 240, 3-46.

Hayashi, K. I., Fujisawa, H., Holland, H. D. \& Ohmoto, H. (1997). Geochemistry of 1.9 Ga sedimentary rocks from Northeastern Labrador, Canada. Geochemica et Cosmochimica Acta, 61(19), 41154137.

Hein, J.R. (2004) Cobalt-rich ferromanganese crusts: Global distribution, composition, origin and research activities. In Workshop on Minerals Other than Polymetallic Nodules of the International Seabed Area, Int. Seabed Auth,. (pp. 188-256). Kingston, Jamaica.

Hein, J. R., Conrad, T. A. \& Staudigel, H. (2010). Seamount Mineral Deposits: A Source of Rare Metals for High-Technology Industries. Oceanography, 23(1), 184-189.

Hein, J. R. \& Koschinsky, A. (2014). Deep-ocean ferromanganese crusts and nodules. In: H.D. Holland, K. K. Turekian (Eds.), Second edition Treatise on Geochemistry, 13, 273-291.

Hein, J. R., Koschinsky, A., Halbach, P., Manheim, F.T., Bau, M., Kang, J-K. \& Lubick, N. (1997). Iron and manganese oxide mineralization in the Pacific, In: K. Nicholson, J.R. Hein, B. Bühn, S. Desgupta (Eds.) Manganese Mineralization: Geochemistry and Mineralogy of Terrestrial and Marine Deposits (pp.123-138). Geological Society of London Special Publication.

Hein, J. R., Schulz, M.S., Dunham, R. E., Stern, R. J. \& Bloomer, S. H. (2008). Diffuse flow hydrothermal 
manganese mineralization along the active Mariana and southern Izu-Bonin arc system, western Pacific. Journal of Geophysical Research, 113(8), 1-29.

Helvacı, C. (2021). Sözlü Görüşme. Dokuz Eylül Üniversitesi, Jeoloji Mühendisliği Bölümü, İzmir.

Holtstam, D. \& Mansfield, J. (2001). Origin of a carbonate-hosted $\quad \mathrm{Fe}-\mathrm{Mn}$-(Ba-As-Pb-Sb-W) deposit of Långban-type in central Sweden. Mineralium Deposita, 36(7), 641-657.

IUCN (International Union for Conservation of Nature Issues Brief) (2018). Deep-sea mining. https:// www.iucn.org/resources/issues-briefs/deep-seamining.

Jones, B. \& Manning, D.A.C. (1994). Comparison of geochemical indices used for the interpretation of palaeoredox conditions in ancient mudstones. Chemical Geology, 111(1-4), 111-129.

Josso, P., Pelleter, E., Pourret, O., Fouquet, Y., Etoubleau, J., Cheron, S. \& Bollinger, C. (2017). A new discrimination scheme for oceanic ferromanganese deposits using high field strength and rare earth elements. Ore Geology Reviews, 87:3-15.

Kandemir, T. (2021). Demirciler (Dursunbey, Balikesir) Radyolarit-Çörtlerle İlişkili Manganez Oluşumlarının jeokimyasal özellikleri [Yayımlanmamış Yüksek Lisans Tezi]. Balıkesir Üniversitesi, Fen Bilimleri Enstitüsü.

Kang, J., Zhang, Z., Zhang, D., Huang, H., Dong, S. \& Zhang, S. (2011). Geochronology and Geochemistry of the Radiolarian Cherts of the Mada'er Area, Southwestern Tianshan: implications for Depositional Environment. Acta Geologica Sinica, 85(4), 801-813.

Karakuş, A., Yavuz, B. \& Koç, Ş. (2010). Mineralogy and Major-Trace Element Geochemistry of the Haymana Manganese Mineralizations, Ankara, Turkey. Geochemistry International, 48(10), 1014-1027.

Kato, Y., Yamaguchi, K.E. \& Ohmoto, H. (2006). Rare earth elements in Precambrian banded iron formations: Secular changes of $\mathrm{Ce}$ and $\mathrm{Eu}$ anomalies and evolution of atmospheric oxygen. In: S.E. Kesler, H. Ohmoto (Eds.). Evolution of Early Earth's Atmosphere, Hydrosphere, and Biosphere-Constraints from Ore Deposits. Geological Society of America, 198, 269-289.

Kemkin, I. \& Kemkina, R.A. (2020). Comparative geochemical study of the cherty rocks of the Taukha terrane (Sikhote-Alin) and its paleogeodynamic significance. Acta Geochimica, 39(4), 539-560.

Kılıç, G., Aydoğan, M.S. \& Kumral, M. (2018). Preliminary results of the radiolarian-chert hosted manganese deposit within the Vezirler ophiolitic mélange (Kula-Manisa, western Turkey): constraints on the origin, paleo-redox conditions, and depositional environments. Arabian Journal of Geosciences, 11(628), 1-22.

Klein, R. T., Lohmann, K. C. \& Thayer, C. W. (1996). $\mathrm{Sr} / \mathrm{Ca}$ and ${ }^{13} \mathrm{C} /{ }^{12} \mathrm{C}$ ratios in skeletal calcite of MytiZus trossulus: covariation with metabolic rate, salinity, and carbon isotopic composition of seawater. Geochimica et Cosmochimica Acta, 60(21), 4207-4221.

Koç, Ş., Özmen, Ö. \& Öksüz, N. (2000). Geochemistry characteristic of Kasımağa (Keskin-Kırıkkale) manganese oxide mineralizations. Bulletin of the Mineral Research and Exploration, 122, 107-118.

Kunimaru, T., Shimizu, H., Takahaski, K. \& Yabuki, S. (1998). Differences in geochemical features between Permian and Triassic cherts from the southern Chichibu terrane, Southwest Japan: REE abundances, major element compositions and $\mathrm{Sr}$ isotope ratios. Sedimentary Geology, 119, 195217.

Kuşçu, M. \& Gedikoğlu, A. (1989). Ulukent (Tavas-Denizli) güneyi manganez yataklarının jeokimyasal özellikleri. Yerbilimcinin Sesi, 17, 29-48.

Lan, C., Yang, A. Y., Wang, C. \& Zhao, T. (2019). Geochemistry, U-Pb zircon geochronology and $\mathrm{Sm}-\mathrm{Nd}$ isotopes of the Xincai banded iron formation in the southern margin of the North China Craton: implications on Neoarchean seawater compositions and solute sources. Precambrian Research, 326, 240-257.

Laurilla, T. E., Hannington, M. D., Petersen, S. \& Garbe-Schönberg, D. (2014). Early depositional of metalliferous sediments in the Atlantis II Deep of the Red Sea: evidence from rare earth element geochemistry. Geochimica et Cosmochimica Acta, 126, 146-168. 
Lei, R-X., Zhang, K., Muhtar, M. N. \& Wu, C-Z. (2020). Neoproterozoic non-glaciogenic iron formation: Insights from $\mathrm{Fe}$ isotope and elemental geochemistry of the Shalong iron formation from the Central Tianshan block, southern Altaids. Precambrian Research, 351, Article 105959. https://doi.org/10.1016/j.precamres.2020.105959.

Li, X. (2000). Geochemistry of the Late Paleozoic radiolarian cherts within the NE Jiangxi ophiolite melange and its tectonic significance. Science in China Series D: Earth Sciences 43(6), 617-624.

Li, S., Yan, J., Pei, Q., Sha, J., Mou, S. \& Xiao, Y. (2019). Risk Identification and Evaluation of the Long-term Supply of Manganese Mines in China Based on the VW-BGR Method. Sustainability, 11(9), 1-23.

Lotfi, M., Kahrazehi, M. \& Ghaderi, M. (2017). Geochemistry and origin of Dehoo manganese deposit, south Zahedan, southeastern Iran. Arabian Journal of Geosciences, 10(142), 1-17.

Lu, Z. L., Ling, H. F., Zhou, F., Jiang, S.Y., Chen, X. M. \& Zhou, H. Y. (2005). Variation of the Fe/Mn ratio of ferromanganese crusts from the Central North Pacific: implication for paleoclimate changes. Progress in Natural Science, 15, 530-537.

Maynard, J. (2010). The chemistry of manganese ores through time: a signal of increasing diversity of earthsurface environments. Economic Geology, $105,535-552$.

McLennan, S. M. (1989). Rare earth elements in sedimentary rocks: influence of provenance and sedimentary processes. In: B.R. Lipin, G.A. McKay (Eds.), Geochemistry and Mineralogy of Rare Earth Elements (pp. 168-200). Mineralogical Society of America Reviews in Mineralogy, Washington.

Moix, P. \& Goricán, Š. (2013). Jurassic and cretaceous radiolarian assemblages from the Bornova mélange in northern Karaburun peninsula (western Turkey) and its connection to the İzmir-Ankara mélanges. Geodinamica Acta, 26(1-2),56-67.

Morford, J. L. \& Emerson, S. (1999). The geochemistry of redox sensitive trace metals in sediments. Geochimica et Cosmochimica Acta, 63(11-12), 1735-1750.
MTA (2002). Türkiye Jeoloji Haritaları, (Ed.: M. Şenel, Düzenleyen: N. Turhan). Maden Tetkik ve Arama Genel Müdürlüğü. 1/500.000 ölçekli Türkiye Jeoloji Haritası, Ankara Paftas1.

Murray, R.W. (1994). Chemical criteria to identify the depositional environment of chert: general principles and applications. Sedimentary Geology, 90, 213-232.

Murray, R.W., Buchholtz ten Brink, M.R., Jones, D.L., Gerlach, D.C. \& Russ, G.P. (1990). Rare earth elements as indicators of different marine depositional environments. Geology, 18, 268-271.

Murray, R. W., Buchholtz ten Brink, M.R., Gerlach, D. C., Russ, G. P. \& Jones, D. L. (1991). Rare earth, major and trace elements in chert from the Franciscan Complex and Monterey Group, California; assessing REE sources to fine-grained marine sediments. Geochemica et Cosmochimica Acta, 55, 1875-1895.

Murray, R. W., Jones, D. L. \& Buchholtz ten Brink, M. R. (1992). Diagenetic formation of bedded chert: Evidence from chemistry of the chert-shale couplet. Geology, 20(3), 271-274.

Naeher, S., Gilli, A., North, R. P., Hamann, Y. \& Schubert, C. J. (2013). Tracing bottom water oxygenation with sedimentary $\mathrm{Mn} / \mathrm{Fe}$ ratios in Lake Zurich, Switzerland. Chemical Geology, 352, 125-133.

Nicholson, K. (1992). Contrasting mineralogicalgeochemical signatures of manganese oxides; guides to metallogenesis. Economic Geology, 87, 1253-1264.

Nicholson, K., Nayak, V. K. \& Nanda, J. K. (1997). Manganese ores of the Ghoriajhor-Monmunda area, Sundergarh District, Orissa, India: geochemical evidence for a mixed Mn source. In: K. Nicholson, J.R. Hein, B. Bühn \& S. Dasgupta (Eds.), Manganese mineralization: Geochemistry and Mineralogy of Terrestrial and Marine Deposits. Geological Society London Special Publication, 119, 117-121.

Nothdurft, L. D., Webb, G. E. \& Kamer, B. S. (2004). Rare earth element geochemistry of Late Devonian reefal carbonates, Canning Basin, Western Australia: confirmation of a seawater REE proxy in ancient limestones. Geochemica et Cosmochimica Acta, 68, 263-283. 
Okay, A. I. (1986). High pressure/low temperature metamorphic rocks of Turkey. In: B.W. Evans, \& E. H. Brown (Eds.), Blueschists and Eclogites, Geological Society of America, 164, 333-348.

Okay, A.I. \& Tüysüz, O. (1999). Tethyan sutures of northern Turkey. In: B. Durand, L. Jolivet, F. Horváth, M. Séranne (Eds.) The Mediterranean basins: tertiary extension within the alpine orogen. Geological Society, London, Special Publications, 156, 475-515.

Okay, A. I. \& Göncüoğlu, M. C. (2004). The Karakaya Complex: A Review of Data and Concepts. Turkish Journal of Earth Sciences, 13, 77-95.

Olivarez, A. M. \& Owen, R. M. (1989). REE/Fe variations in hydrothermal sediments: Implications for the REE content of seawater. Geochemica et Cosmochimica Acta, 53, 757-762.

Owen, A., Armstrong, H. \& Floyd, J. (1999). Rare earth elements in chert clast as provenance indicators in the Ordovician and Silurian of the Southern Uplands of Scotland. Sedimentary Geology, 124, 185-195.

Oygür, V. (1990). Çayirli (Ankara-Haymana) Manganez Yatağinin Jeolojisi, Oluşumu ve Kökeni Üzerine Görüşler. Maden Tetkik ve Arama Dergisi, 110, 29-43.

Öksüz, N. (2011a). Geochemical characteristics of the Eymir (Sorgun-Yozgat) manganese deposit, Turkey. Journal of Rare Earths, 29(3), 287-296.

Öksüz, N. (2011b). Geochemistry and the Origin of Manganese Mineralizations in Derbent (Yozgat) Region. Bulletin of the Earth Sciences Application and Research Centre of Hacettepe University, 32(3), 213-234

Öksüz, N. \& Okuyucu, N. (2014). Mineralogy, Geochemistry, and Origin of Büyükmahal Manganese Mineralization in the Artova Ophiolitic Complex, Yozgat, Turkey. Journal of Chemistry, 2014, 1-11. https://doi.org/10.1155/2014/837972.

Özkan, M., Çelik, Ö. F., Soycan, H., Çörtük, R. M. \& Marzoli, A. (2020). The Middle Jurassic and Early Cretaceous basalt-radiolarian chert association from the Tekelidağ Mélange, eastern IzmirAnkara-Erzincan suture zone (northern Turkey). Cretaceous Research, 107, 104-280.
Öztürk, H. (1997). Manganese Deposits in Turkey: Distribution, Types and Tectonic Setting. Ore Geology Reviews, 12, 187-203.

Öztürk, H. \& Hein, J. R. (1997). Mineralogy and Stable Isotopes of Black Shale-Hosted Manganese Ores, Southwestern Taurides, Turkey. Economic Geology, 92(1), 733-744.

Öztürk, H., Kasapçı, C., Cansu, Z. \& Hanilçi, N. (2016). Geochemical characteristics of iron ore deposits in central eastern Turkey: an approach to their genesis. International Geology Review, 58(13), 1-18.

Öztürk, H., Kasapçı, C. \& Özbaş, F. (2019). Manganese Deposits of Turkey. In: F. Pirajno, T. Ünlü, C. Dönmez \& M.B. Şahin (Eds.) Mineral Resources of Turkey (pp. 261-282). Springer Verlag.

Patacca, E., Scandone, P., \& Giunta, G. (1979). Mesozoic paleotectonic evolution of the Ragusa zone (Southeastern Sicily). Geologica Romana, 18, 331-369.

Petersen, S., Kratschell, A., Jamieson, J., Hein, J. R. \& Hannington, M. D. (2016). News from the seabed - Geological characteristics and resource potential of deep-sea mineral resources. Marine Policy, 70, 175-187.

Piepgras, D. J. \& Jacobsen, B. (1992). The behavior of rare earth elements in seawater: precise determination of variations in the North Pacific water column. Geochemica et Cosmochimica Acta, 56, 1851-1862.

Polgári, M., Hein, J. R., Vigh, T., Szabó-Drubina, M., Fórizs, I., Bíró, L., Müller, A. \& Tóth, A.L. (2012). Microbial processes and the origin of the Úrkút manganese deposit, Hungary. Ore Geology Reviews, 47, 87-109.

Robertson, A., Parlak, O., Ustaömer, T., Tasl1, K., İnan, N., Dumitrica, P. \& Karaoğlan, F. (2014). Subduction, ophiolite genesis and collision history of Tethys adjacent to the Eurasian continental margin: New evidence from the Eastern Pontides, Turkey. Geodinamica Acta, 26, 230-293.

Rojay, B., Altıner, D., Özkan-Altıner, S., Önen, A. P., James, S. \& Thirlwall, M. F. (2004). Geodynamic significance of the cretaceous pillow basalts from north Anatolian Ophiolitic Mélange (Central Anatolia, Turkey): geochemical and 
paleontological constraints. Geodinamica Acta 17, 349-361.

Roy, S. (1997). Genetic diversity of manganese deposition in the terrestrial geological record. In: K. Nicholson, J.R. Hein, B. Buhn \& S. Dasgupta (Eds.) Manganese Mineralization: Geochemistry and Mineralogy of Terrestrial and Marine Deposits. Geological Society, Special Publication, London 119, 5-27.

Sakhno, V. G. (2008). Recent and present-day volcanism in the southern Far East [in Russian]. Dal'nauka, Vladivostok.

Santantonio, M., Scrocca, D., \& Lipparini, L. (2013). The Ombrina-Rospo Plateau (Apulian Platform): Evolution of a Carbonate Platform and its Margins during the Jurassic and Cretaceous. Marine and Petroleum Geology, 42, 4-29.

Sarıfakıŏglu, E., Dilek, Y. \& Sevin, M. (2017). New synthesis of the Izmir-Ankara-Erzincan suture zone and the Ankara mélange in northern Anatolia based on new geochemical and geochronological constraints. In: R. Sorkhabi (Ed.) Tectonic Evolution, Collision, and Seismicity of Southwest Asia: In Honor of Manuel Berberian's Forty-Five Years of Research Contributions: Geological Society of America Special Paper, 525.

Sugisaki, R. (1984). Relation between chemical composition and sedimentation rate of Pacific Ocean-floor sediments deposited since the middle cretaceous: basic evidence for chemical constraints on depositional environments of ancient sediments. The Journal of Geology, 92(3), 235-259

Sugisaki, R., Yamamoto, K. \& Adachi, M. (1982). Triassic bedded cherts in central Japan are not pelagic. Nature, 298, 644-647.

Sugitani, K., Horiuchi, Y., Adachi, M. \& Sugisaki, R. (1996). Anomalously low $\mathrm{Al}_{2} \mathrm{O}_{3} / \mathrm{TiO}_{2}$ ratios for Archean cherts from the Pilbara Block, Western Australia-possible evidence for extensive chemical weathering on the early earth. Precambrian Research, 80, 49-76.

Şaşmaz, A., Türkyılmaz, B., Öztürk, N., Yavuz, F. \& Kumral, M. (2014). Geology and geochemistry of Middle Eocene Maden complex ferromanganese deposits from the Elazığ-Malatya region, eastern Turkey. Ore Geology Reviews, 56, 352-372.
Şaşmaz, A., Zagnitko, V.M. \& Şaşmaz, B. (2020). Major, trace and rare earth element (REE) geochemistry of the Oligocene stratiform manganese oxidehydroxide deposits in the Nikopol, Ukraine. Ore Geology Reviews, 126, 103772.

Şaşmaz, A., Şaşmaz, B., Hein, J.R. (2021). Geochemical approach to the genesis of the Oligocene-stratiform manganese-oxide deposit, Chiatura (Georgia). Ore Geology Reviews, 128, Article 103910. https://doi. org/10.1016/j.oregeorev.2020.103910.

Şengör, A. M. C. \& Yılmaz, Y. (1981). Tethyan evolution of Turkey: a plate tectonic approach. Tectonophysics, 75, 181-241.

Takematsu, N., Sato, Y. \& Okabe, S. (1989). Factors controlling the chemical composition of marine manganese nodules and crusts: a review and synthesis. Marine Chemistry, 26(1), 41-56.

Taylor, S. R. \& McLennan, S. M. (1985). The continental crust: its composition and evolution. Blackwell, Oxford

Tekin, U.K. (1999). Biostratigraphy and systematics of late middle to late Triassic radiolarians from the Taurus mountains and Ankara region, Turkey. Geol Paläont Mitt. Innsbruck, Sonderband 5: $1-296$

Tekin, U. K., Göncüoğlu, M. C. \& Turhan, N. (2002). First evidence of late Carnian radiolarians from the Izmir-Ankara suture complex, Central Sakarya, Turkey: implications for the opening age of the Izmir-Ankara branch of neo-Tethys. Geobios, 35(1),127-135.

Tekin, U. K., Göncüoğlu, M. C., Özkan-Altıner, S. \& Yalınız, M.K. (2006). Dating of Neotethyan volcanics by planktonic fauna, Bornova flysch zone, NWAnatolia (unpublished).

Tekin, U. K. \& Göncüoğlu, M. C. (2007). Discovery of oldest (late Ladinian to middle Carnian) radiolarian assemblages from the Bornova flysch zone in western Turkey: implications for the evolution of the Neotethyan Izmir-Ankara Ocean. Ofioliti, 32(2),131-150.

Tekin, U. K. \& Göncüoğlu, M. C. (2009). Late middle Jurassic (late Bathonianearly Callovian) radiolarian Cherts from the Neotethyan Bornova flysch zone, Spil Mountains, Western Turkey. Stratigraphy and Geological Correlation, 17(3), 298-308. 
Toth, J. R. (1980). Deposition of submarine crusts rich in manganese and iron. Geological Society of America Bulletin, 91, 44-54.

U.S. Geological Survey (USGS). Mineral Commodity Summaries. 2019. Available online: https://doi. org/10.3133/70202434 (accessed on 10 May 2019).

Usui, A. \& Someya, M. (1997). Distribution and composition of marine hydrogenetic and hydrothermal manganese deposits in the northwest Pacific. In: K. Nicholson, J.R. Hein, B. Buhn, S. Dasgupta (Eds.), Manganese Mineralization: Geochemistry and Mineralogy of Terrestrial and Marine Deposits (pp. 177-198). Geological Society Special Publication, London.

Üner, T. (2010). Petrology of Eldivan and Ahlat (Cankiri) ophiolites [Unpublished PhD Thesis]. Ankara: Hacettepe University.

Wegorzewski, A. V. \& Kuhn, T. (2014). The influence of suboxic diagenesis on the formation of manganese nodules in the Clarion Clipperton nodule belt of the Pacific Ocean. Marine Geology, 357, 123-138.

Wignall, P. B. \& Myers, K. J. (1988). Age and geochemistry of late Precambrian sediments of the Hammamat series from the northeastern desert of Egypt. Journal of Geological Society, London, 146, 213-215.

Wonder, J. D., Spry, P. G. \& Windom, K. E. (1988). Geochemistry and origin of manganese-rich rocks related to iron-formation and sulfide deposits, western Georgia. Economic Geology, 83, 10701081.

Wright, J., Schrader, H. \& Holser, W. T. (1987). Paleoredox variations in ancient oceans recorded by rare earth elements in fossil apatite. Geochemica et Cosmochimica Acta, 51(3), 631-644.

Xie, J., Sun, W., Du, J., Xu, W. Wu, L., Yang, S. \& Zhou, S. (2013). Geochemical studies on Permian manganese deposits in Guichi, eastern China: implications for their origin and formative environments. Journal of Asian Earth Sciences, 74, 155-166.
Yılmaz, Y., Tüysüz, O., Yiğitbaş, E., Genç, Ş. C. \& Şengör, A. M. C. (1997). Geology and tectonic evolution of the Pontides. In: A.G. Robinson, (Ed.), Regional and Petroleum Geology of the Black Sea and Surrounding Region. American Association of Petroleum Geologists, 68, 183-226.

Yolsal-Çevikbilen, S., Biryol, C.K., Bech, S., Zandt, G., Taymaz, T., Adiyaman, H. E. \& Özacar, A.A. (2012). 3-D crustal structure along the North Anatolian Fault Zone in north-central Anatolia revealed by local earthquake tomography. Geophysical Journal International, 188, 819-849.

Zarasvandi, A., Lentz, D., Rezaei, M. \& Pourkaseb, H. (2013). Genesis of the Nasirabad manganese occurrence, Fars province, Iran: geochemical evidences. Chemie der Erde Geochemistry, 73, 495-508.

Zarasvandi, A., Rezaei, M., Sadeghi, M., Pourkaseb, H. \& Sepahvand, M. (2016). Rare-earth element distribution and genesis of manganese ores associated with Tethyan ophiolites, Iran: A review. Mineralogical Magazine, 80(1), 127-142.

Zhang, F. F., Yan, B., Guo, Y.L., Zhu, X. K., Zhou, Q. \& Yang, D. Z. (2013). Precipitation from of manganese ore deposits in Gucheng, Hubei province, and its paleoenvironment implication. Acta Geologica Sinica, 87(2), 245-258 (in Chinese with English abstract).

Zhu, X. K., Peng, Q. Y., Zhang, R.B., An, Z. Z., Zhang, F. F., Yan, B., Li, J., Gao, Z. F., Qin, Y. \& Pan, W. (2013). Geological and geochemical characteristics of the Daotuo superlarge manganese ore deposit at Songtao County in Guizhou province. Acta Geologica Sinica 87(9), 1335-1348 (in Chinese with English abstract). 